
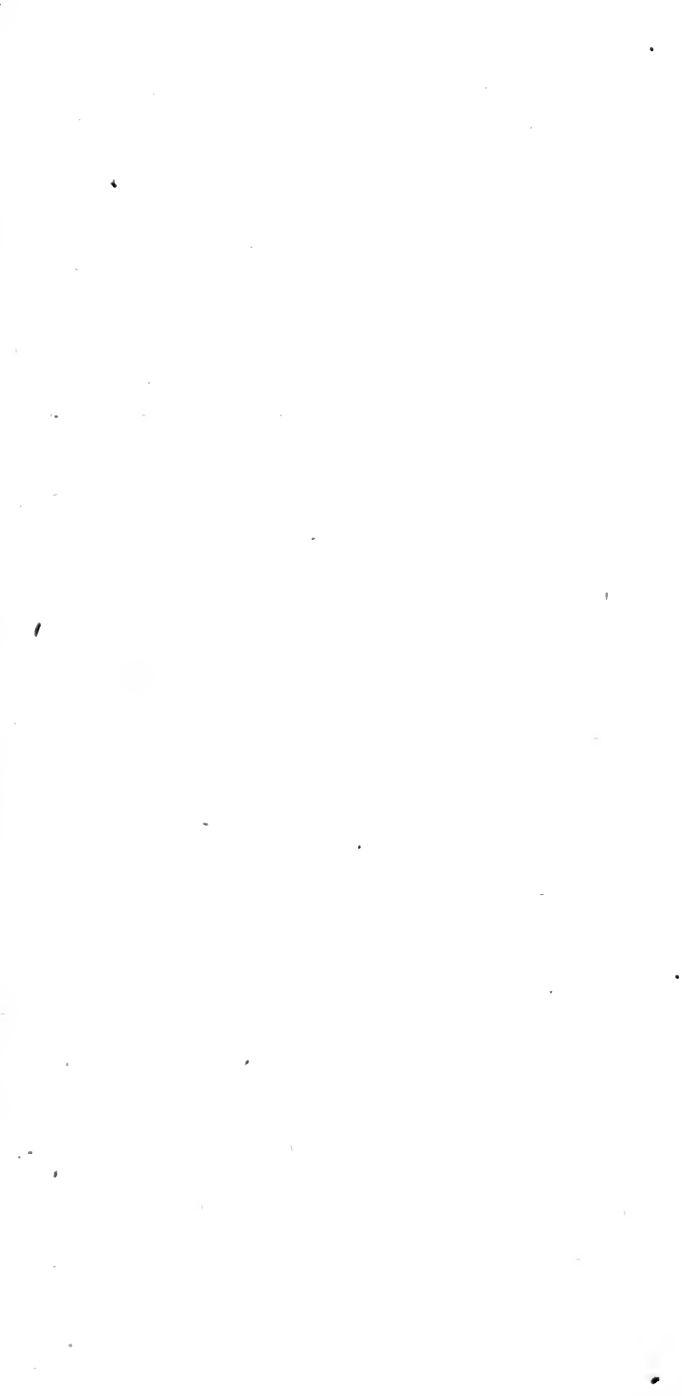

$$
\text { ( }
$$




\section{Digitized by the Internet Archive in 2007 with funding from Microsoft Corporation}


HEREDITY AND SOCIAL PROGRESS 
Ther 


\title{
HEREDITY AND SOCIAL PROGRESS
}

\author{
BY \\ SIMON N. PATTEN \\ WHARTON SCHOOL OF FINANCE AND ECONOMY \\ UNIVERSITY OF PENNSYLVANIA \\ AUTHOR OF "THE DEVELOPMENT OF ENGLISH THOUGHT" \\ "THE THEORY OF PROSPERITY," ETC.
}

New \%ork

THE MACMILLAN COMPANY

LONDON : MACMHILAN \& CO., LTD.

1903

All rights reserved




COPYRIGHT, I903,

By THE MACMILLAN COMPANY.

Set up and electrotyped January, 1903. 
How is the social surplus of an epoch transformed into permanent conditions and mental traits?

Does progress start from a deficit, or from a surplus?

Does genius come by additions, or by differentiation?

Does education improve natural or acquired characters?

Does reform come by strengthening the strong, or by helping the weak? 
"A GREAT lawyer, statesman, and philosopher of a former age - I mean Francis Bacon - said that truth carne out of error much more rapidly than it came out of confusion. There is a wonderful truth in that saying. Next to being right in the world, the best of all things is to be clearly and definitely wrong, because you will come out somewhere. If you go buzzing about between right and wrong, vibrating and fluctuating, you come out nowhere; but if you are absolutely and thoroughly and persistently wrong, you must, some of these days, have the extreme good fortune of knocking your head against a fact, and that sets you straight again." - HuxLEY. 


\section{CONTENTS}

CHAPTER

PAGX

I. THE PROBLEM • . . . . . . I I

II. The Method . . • • • • . 6

III. ACQUiRed Characters . . . . . 16

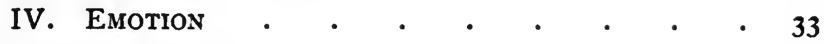

V. Reduction •

VI. RESPONSIVENESS • . . • . . . 62

VII. SENSATION • • • • • • • • • • 77

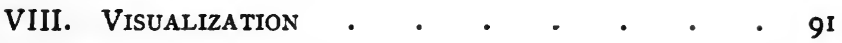

IX. A Possibility . . . . . . . I0I

X. Devolution • • • • • • • • • $\quad$ • 117

XI. Character • . . . . . . . . 129

XII. The INNER ORgans OF EXPRESSION . . . 140

XIII. Some TermS . . . . . . . 156

XIV. Education • . . . . . . . . I64

XV. REFORM . . . . . . . . . I8I

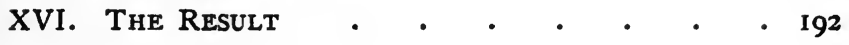





\section{CHAPTER I}

\section{The Problem}

THE social surplus is a part of the annual produce of nations. It is concretely embodied in goods which perish, and must be replaced by renewed effort in each epoch. Nature aids man freely, but not in increasing ratios. The amount of the natural surplus varies, and there are resultant periods of plenty and of scarcity; but a static population ever presses against this limit, and leaves no room for progress, which comes only after conscious effort, and brings with it the social surplus.

Man, in his endeavor to improve his condition, faces a law of diminishing returns. In each epoch the purely natural conditions are a little worse than they were in the preceding, and society would decline, unless men made greater exertions. We picture this in a large way when we say that the sun is the source of all energy, and that the energy steadily wanes. 
We come, however, closer to the real facts when we see that the denuding forces of nature acting on the surface of the earth yearly carry off a portion of the soil and deposit it in useless places or beneath the sea. It may of course be said that these denuding forces make soil as well as destroy it; but the destroying action is in the present and the restoring process is in the future. In each epoch, therefore, men face diminishing natural returns, even though in the end, new soils may be added by the upheaval of submerged regions. The ice of the glacial epoch, for example, may have added much to the fertility of the regions it transformed; and yet the races of that age must have felt that their lot was cast in unpleasant lines.

Since the natural surplus falls off, it cannot be a source of social progress. Men must meet new conditions under more disadvantageous conditions, or they must create a social surplus which more than balances the increasing natural deficit. But even with a social surplus progress is not safe. The surplus is always in perishable goods, which must be 
periodically replaced. If all that society gains from them is the pleasure of their consumption, the presence of a surplus may create prosperity, give an immediate relief from toil, and add much to the fund of current enjoyment; but in the end the periodic replacement of the surplus ceases through the diminution of its resources. To make progress secure, the temporary surplus must be transformed into permanent conditions or into mental traits. If this transformation is not possible, all progress is temporary; if it is possible, then the process of its transformation becomes the key to social progress.

The problem is really simpler than I have here stated it. While permanent conditions may be said to be the peculiar province of the economist, and do attract much of his attention, yet their scope is limited. In fact, little of our material environment has come down from the past, - so that no nation survives which has relied on its permanent improvements. We talk freely about our inherited wealth, and yet, great as is the wealth of the leisure class, but few of the goods of its members 
are as old as themselves. Wealth does not endure, but is constantly replaced from the annual produce. The real source of progress must, therefore, lie in the acquisition of mental traits; even permanent improvements are of little avail until a mental trait arises which causes them to be appreciated.

The situation, then, is this: the natural surplus is steadily decreasing, or at best it merely holds its own; the social surplus is the result of conscious effort, which must so arouse mental traits that natural decreasing returns become socially increasing returns. How, then, is the social surplus, the temporary product of annual effort, transformed into mental traits that abide and become the basis of subsequent progress?

This is the problem stated in terms of economics. The same problem arises in biology, and, as there stated, is: How can acquired characters become natural? Notice that the two questions involve the same points. The social surplus is a consciously created product: it is made by effort after men arrive at maturity. Economic traits are thus ac- 


\section{The Problem}

quired characters. If acquired characters cannot be inherited, then the social surplus cannot be transformed into mental traits, and enduring progress is impossible. Biologists have not considered the first proposition, "the natural surplus is a decreasing one," and they hope that through a natural differentiation of germ cells an unconscious progress may be continued. But if the natural surplus is actually decreasing, the natural differentiation will be regressive, not progressive. Men must stem a naturally adverse tide if they would progress, and unless the result of their effort favorably affect their descendants progress is hopeless. To the solution of this enigma economists as well as biologists must turn. It is not a problem that lies in any one science for the solution of which others must wait. It is the essential problem of all science and appears in some form in every field.' I ask again, how is the social surplus transformed into permanent conditions and mental traits? An answer will be given in the following pages, or at least an endeavor will be made to throw some light on it. 


\section{CHAPTER II \\ The Method}

In the following discussion several logical principles are used as safeguards against error. They must be formulated so that the reader can determine their validity, or at least grant that I have used a consistent method and have not made haphazard guesses.

It is a well-accepted principle that mental and physical phenomena are parallel. Without deciding which is the cause and which the effect, it is easy to see that the presence of a given phenomenon in one field involves some expression of it in the other. The fact of parallelism having been accepted, classifications of differences in the two fields ought to be the same. The actual mental differences must correspond to, and be an expression of, physical differences. So, too, for each physical difference there must be some psychic expression. 
I have used this principle to test the validity of distinctions as they are made by commonly used words in each science. It is too often assumed that distinctions correspond to words, and that when an array of words has been defined, they will be justified by facts in the real world. But language has had so long and so loose a development that the mere presence of words is no evidence of the reality of the distinctions they represent. Usage also gives so broad a meaning to many words that they lap over each other in every conceivable way. They must be pruned to the real differences as they exist in the parallelism of expression in two related fields. The word "emotion," for example, has a great variety of meanings. It can be restricted to one only when we define it by its physical parallel; for since thought and matter are parallel, emotion has its exact physical expression. We may be sure the word stands for something when it is defined in terms of this physical parallel. We can be sure of nothing if usage and custom alone are relied on.

This method of defining may err in unduly 
simplifying the field, but it is an effective remedy for loose language, and the distinctions it permits will have a reality back of them. I have used this test in defining terms and believe it is the only one that suffices to eject the superfluous. The size of dictionaries is partly responsible for loose thinking.

The parallelism of mind and matter is not the only one of which use has been made. I have assumed that there is a similar parallel between economics and biology, using these terms in a broad way as a study of the environment and of life. If the environment and the environed organism are adjusted, the peculiarities of the organism must correspond to those of the environment. To meet each difference in the environment some peculiarity in the organism will have developed to fit it to the situation. The distinctions in organisms run parallel to those in the environment, and those of the one may be expressed in terms of the other. It should be possible, therefore, to find real economic differences by checking against lists of corresponding differences in the organisms adjusted to these situations, - and to test 
the reality of biologic terms by looking for their expression in terms of the environment. This method, again, would give us not only simplicity, but validity, and would dispose of the mass of useless distinctions that crowd both sciences.

The economist establishes laws by observing the use by the individual or by society of concrete goods; while the biologist studies similar relations through the organism which utilizes the goods. Economics implies a conscious economy, and is perhaps too narrow for an inclusive classification. The term "ecology" has been suggested, and perhaps it makes a clearer analysis. It is not for words that I contend, but for the identity of the phenomena. There should be a science of the environment as a source of nutriment and protection to animal life whose distinctions should parallel those of biology.

Using these parallels of expression, many aids are obtained in transforming secondary into primary laws. Secondary laws are based on the observed facts in a single field. They are raised to primary laws by extending their 
scope so that many independent inductions are summed up in one law. Facts of no prominence in one science become important as soon as they are perceived to express in a new way the generalizations in another field. What has the falling of an apple to do with the movements of the moon? Nothing until the two are known to be expressions of the same law. When a generalization in one science acquires the position of a secondary law, if expressions of the same law can be found in the parallel science, there is firm ground for believing that the generalization can be elevated to a primary law. The parallelism of the expression is the best evidence that really elementary principles have been reached. When, for example, I perceived that emotion is destructive of tissue and tends toward simplicity, I sought in biology some expression of the same process, and found the reduction in connection with germ cells - the same phenomenon in a very different form. I assumed that these independent facts are expressions of a primary law of far wider reach than the generalizations about them made in either science. In this 
way seemingly incomplete generalizations are raised to a higher rank and given a validity that a multitude of facts in one field would not insure them. I do not mean to assert that this method may not lead to error, but I do claim that it is legitimate and will eliminate the errors into which deductive reasoning sinks. In every case where this method has been used I have sought for parallel expressions, and finding them, have assumed that I was on the track of a general law which ought to be formulated. The value of facts is thereby raised and laws are thrown into a more general form than if a purely inductive method were followed. Grant that the theory of parallelism is correct, and the broader generalizations will at least deserve consideration. They are not the result of a guess, but of a method persisted in through a long period.

The following rules are applications of this method and efficient checks to error:-

I. A principle cannot be accepted as the basis of a working hypothesis until at least one instance of its action is known.

2. The presumption is against an explana- 
tion that demands a new principle instead of one that is known to be active in other cases.

3. Not until an old principle fails to explain all cases brought under it is it legitimate to introduce a new principle.

4. A basis of explanation in a known principle is more valid than an explanation involving an unknown principle.

5. If a few elements are repeatedly used to make a complex organism, it is highly probable that all possible combinations have already been made, and therefore it is also probable that instances of every combination are in existence or have existed. The presumption of a general law is in favor of a hypothesis as soon as single instances of its operation are discovered.

6. Links missing in the verification of a chain of reasoning do not render a hypothesis improbable.

7. The principle of chance must never be admitted.

8. Whenever a specific form is found, variations from this form may be assumed. This is involved in the theory of evolution by which 
constant changes are made from one form to others.

9. A law having parallel expressions in two fields has greater validity than a complete induction in one field.

I0. If the causes of present changes are sufficient to account for past changes, they should.also be accepted for the latter.

There is in this last rule an importance not at first apparent. The principle of parallelism is well illustrated by the relation of geography to geology. Geography is a study of the earth as it is, including all its present changes. Geology is a study of it as it has developed through successive stages. Geology is thus a long series of past geographies. There were no forces at work in any of them that are not now active. Forces may, it is true, be obscure and subordinate at the present time, but they are here, and it is through their study that the great changes of the past are made manifest. We have few glaciers, but it is through them that the puzzles of the glacial epoch were solved. The denuding forces of air and water seem 
slight, but it is through their agencies, acting perhaps no more rapidly than at present, that great mountain ranges were lowered. The present changes throw light on the past, and the study of former changes is necessary to a knowledge of the present. It has been happily said, "Geology is the study of the past in the light of the present, while geography is a study of the present in the light of the past."

Do we not observe the same relations between biology and economics? The more elementary forms of life and the lower animals may be said to be the past of human evolution as geology is the past of physical evolution. Each organism was a changing being and then became a fixed type. Man, however, is changing; all the forces that have ever been at work on organisms are still at work on him. He has upbuilding forces and denuding forces; they may be studied in actual operation just as the changes due to natural forces may still be studied in geography.

The laws of human evolution are the laws of natural evolution, and the order of its 


\section{The Method}

changes is the order of nature. It is a false assumption which forces the categories of animal life on human life and attempts to explain the latter by the former. Human life is conscious life, and human progress is conscious progress. In every field of endeavor, conscious acts precede those which are unconscious; consciously acquired character is the antecedent of the natural character. If our logical canon is correct, this order is the order of nature, and lower life passes through the same stages when it is in mobile evolution. I would therefore raise the inductions concerning human life into primary laws and affirm that its principles are of general application. What is happening has happened, and the course of its happening is the course of all happenings. Vital forces are to-day what they always have been, and it is a false premise which assumes that past changes were due to forces now extinct or of so little potency that the natural order of progress is changed. 


\section{CHAPTER III}

\section{Acquired Characters}

THE simplest and most obvious theory of heredity is that of growth through use and of organic change through the accumulated effects of use. It is plain that activity causes organs to grow. The laborer acquires additional strength by using his arms or his hands to do a particular sort of work. Those who walk regularly find that they can go farther than before the regular exercise began. Blacksmiths have strong arms, musicians have dexterous fingers, and porters have strong legs and backs. It is not necessary to give extended examples of what every one knows. Even the crudest observations verify the law that use precedes and is the cause of growth and change.

Differences of opinion, however, arise when it is asserted that these organs, developed through use, are inherited by descendants in their improved form. There can, of course, 
be no doubt that children resemble their parents, but do they resemble parents in those characters which have been modified by use? The answer will depend upon the observer. If he thinks of the general adjustment of each race to its special environment, he perceives that it has developed those qualities, aptitudes, and traits that are of special use in that environment. It would seem, therefore, from this general resemblance of son to father, that the qualities of the father have reappeared in the son; but how this has been done remains unanswered. Selection may have displaced those not inheriting the useful modifications, or the organism of the child may have been directly modified by the changes that took place in the parent.

Although there is little direct evidence to support either theory, there is indirect evidence which seems decisive. If children inherited the acquired qualities of parents, they would naturally and cheerfully do those acts and establish those relations that the parents have found useful in their struggle for survival. Parents have to teach children what they have 
found useful; they must put pressure on children to make them accept their own avocation and mental attitude; the standards and habits of each generation must be instilled into the succeeding generation. Every stable race is careful to impress on the young its habits, standards, and moral code. Surely this would not be necessary if every modification in the parent were directly inherited by the child. The experience of the race seems to negative the idea of the ready inheritance of acquired characters, and to affirm that they do, in some way, become natural characters. If not by direct descent, where, then, is the road?

Let us follow the process of acquisition more carefully, and perhaps its method will become more obvious. Some of the individuals in a given environment perceive that a new process or a new mode of adjustment, demanding, we will assume, a stronger arm or a firmer grasp, will give them an advantage or offer a greater return. The process, often repeated, develops the muscles of the arm and causes a larger return, let us say, of wheat, to be produced. After this fact is discovered by 
individuals, others, seeing that an advantage is derived, will imitate the deeds of the inventors and acquire the stronger arms due to increased use. Imitation will cause this habit to spread and will keep in the community the people who see the advantage of the acquired character, and through use voluntarily develop it. Children will also, through the example of parents, submit to the discipline needed to develop it, and thus it will be handed down from generation to generation as an acquired character. But not all the members of the community, and especially not all the children, will submit to the needed discipline, but will follow their natural inclinations and act in ways that do not develop the needed character. As a result they suffer from the lack of those articles of food obtained by its means. To coerce them, and especially to prevent children from suffering the consequences of following their natural bent, moral rules and local customs are devised which force on all members of the community the acquisition of traits and characters that, in the opinion of the majority, are necessary toward 
well-being. In some such way the discov. eries and inventions of the few are extended and their use is enforced, until the whole community, acting in harmony with the local code and moral tradition, acquires and keeps the characters demanded for the best utilization of the environment. Many acquired characters are handed down from generation to generation, a fact in proof that acquired characters are not of necessity inherited. If they were, the great mass of customs, habits, and local traditions would not be needed, society would be organized on a simple basis, and every son would do naturally that which the father did through effort. When, therefore, an improvement is made, the whole community is fastened to the environment by a conscious process which imposes the new activity upon all, and prevents any one from utilizing surrounding conditions in a less effective way than that prescribed by the more efficient. The new conditions are generalized and perpetuated by methods which show that acquired characters are not of necessity transformed into natural characters. Certainly social customs are not based 
on this thought; naturalness has some other source.

If characters acquired by use are not directly inherited, a clew to the acquisition of natural characters may be obtained by a study of the changed relations of parent and child, brought about by the parents' acquired characters. We know that acquired characters have an economic use and permit a surer or a more abundant supply of economic goods, whereby the food is improved or new methods of obtaining it are devised; or perhaps some method of defence is invented by which the situation may be better utilized than before. Certainly no action would be persisted in long enough to make it an acquired character, either of an individual or of a community, unless it gave a decisive advantage to its possessors. It may, therefore, be assumed that the new character gives to its possessors more food, leisure, or protection, and that some of these advantages will be shared by their children, who will have better food and a longer period of childhood in which to develop their natural qualities. While some parents might use the acquired 
character solely for their own advantage, not only would the majority share it with their children, but social custom and morality would force them to admit their children to some of its advantages. What changes, then, would this better food and longer childhood effect in the new generation? An increased nutrition creates more energy, and this energy will be used to develop the natural qualities more fully than earlier conditions permitted. A longer childhood will have the same effect. Children play instead of work, and the incipient qualities which might fail to develop in a shorter childhood would now become prominent characters and elements in determining the activities of the child. When this child, becoming a man, chooses his vocation, he will not accept the discipline or the occupation of his father, or so live as to develop his acquired characters. The old discipline will be distasteful to him in proportion as his increased energy and longer period of childhood have differentiated his inclinations from those of the parent. He will, therefore, have a strong impetus to move into a new world or to seek 
at home a new occupation in which his natural characters will be more effective than in the old.

When, for example, a bricklayer has improved his condition by the acquired characters of his occupation, and has, as a consequence, bettered the position of his children, they tend to become clerks and mechanics; the sons of mechanics become storekeepers, foremen, and superintendents, while the children of farmers become business men, lawyers, and clergymen. It is well known that the children of any class move into the class above them when the economic welfare of parents is so improved that children have more food, shelter, and leisure. This means that natural inclinations and more energy are used to break from the routine of parents and to enter occupations where the new energy and the stronger natural inclinations count for more in the success of the undertaking. There is a movement of population with every increase of energy, and with every opportunity to develop the inherent qualities born in men.

If this well-known tendency be formulated 
into a general law, it will be this: acquired characters are not inherited, but the improved situation of parents who acquire characters gives to their children more vitality and better opportunities to develop their natural qualities, and results in new qualities which the children utilize by a change of occupation or environment. In short, every acquired quality increases energy, and the additional energy starts a movement toward a new environment. Putting this fact in another way, it may be said that present environments do not make the qualities of those who live in them, but that people seek these environments because they have the characters necessary to their utilization. Qualities are an index of energy, and energy determines the environment that a man seeks. The adjustment to it is not the cause of the qualities, but a result of their presence. What men have of natural character, they acquired in some other environment. Acquired characters only are the result of present conditions, and when they have had their proper effect in the increase of energy, another shifting of environments results, by 
which the new natural characters will find a place and be the means of a new increase of energy and another shifting of environments.

This principle, broader than human society, is a general law, and is recognized in biology under the head of secondary sexual qualities. Darwin assumes that the peculiar characters of males are due to the contests of rival males or to sexual selection caused by females choosing those males in whom the qualities are most prominent. Geddes and Thompson, ${ }^{1}$ however, point out that these secondary qualities are expressions of a natural characteristic of male animals. 'The males are more katabolic than the females, and from their activity results the qualities called secondary. The emphasis is thus placed on the natural effect of surplus energy, which shows itself more prominently in males than in females. If energy expresses itself in activity, and activity causes growth, there would seem to be no need of other explanations for sexual characters of males. When males enter into severe contests among themselves, their primary characters must be 1 "The Evolution of Sex," Chap. I. 
more fully developed than the mere necessities of life demand. The successful contestant would be the one with the most energy, and this energy would also find an outlet in changes which create secondary qualities. The fighting males would grow; the surplus energy speeding in one direction would also find exit in the other. Secondary sexual characters are the natural expression of surplus energy created by acquired characters. At least they appear under improved conditions or when nutrition is superabundant, and are naturally associated with surplus energy. They suggest a way in which surplus energy can effect organic changes in harmony with welldemonstrated biological laws.

If sexual characters are natural expressions of surplus energy, they give a clew as to how other characters are formed. They seem not to be a class by themselves, but to reflect the superior vitality of males. Should any of these characters prove useful, not merely in contest but also in the acquisition of nutriment, they would be acquired through inheritance by females as well as by males, and so become 
necessary characters. It is a well-known fact that males are more variable than females and that new qualities are usually first acquired by them. Females then acquire what has proved useful; representing in their progress the net results of past development as it is shown in inherited structure. The order of the change from acquired to natural characters is: first, a surplus of energy following acquired characters; second, the expression of this energy in the secondary sexual characters of the males; third, the discovery of some use for these secondary characters in which the whole race or species can participate; and fourth, their appearance through heredity in all individuals of the species, whereupon they cease to be secondary and become primary characters.

We note here three kinds of characters primary, acquired, and secondary. The primary are those at a given moment necessary to the existence of an organism. The acquired are those due to individual action, and they are propagated by imitation, forethought, or some other conscious means. The secondary result from the success of the acquired characters in 
giving nutrition and energy in excess of the needs of mere existence and propagation. Secondary characters are not necessary to the acquisition of energy, but are the natural expressions of it when acquired. They often prove useful because they permit a change in the habits or the environment of organisms; and in the new situation, or under the new conditions, they become as essential to the new form of existence as the primary characters were. The difference between the two groups of characters having now disappeared, they both may be classed as primary. In this way the number of essential characters may gradually increase. The non-essentials of a simple life become the essentials of the more complex. Each new environment tends to develop acquired characters through which it is better utilized, and these become primary by a movement into a new environment. Use is not the cause of characters but a result of their appearance. It is of course true that most characters have a use, but this fact is a consequence of the multitude of environments into which organisms can go. Any combination of characters may 
prove advantageous in struggle if the organism possessing it is put in the proper environment.

In harmony with this thought, I would say animals do not develop teeth because they eat hard food. They eat hard food because they have teeth. They do not attain wings because they fly; they fly because they have wings. They do not develop nails because they scratch; they scratch because they have nails. Nor do they develop hair because they go into cold regions; they go north because they have hair. By this I mean that the tooth, the nail, the wing, the hair, and other specific characters appear as secondary qualities, and are at first merely expressions of surplus energy. A use is found for an organ already in existence through other causes, and then by development and selection it becomes an efficient instrument. Use does not cause anything; it only modifies and improves what other causes have already formed.

The limited extent to which use is available in creating organic changes is illustrated by what Professor Cope called the doctrine of 
the unspecialized. ${ }^{1}$ The parts most used and hence of the greatest importance to animals become highly specialized in their mechanism and restrict activity within fixed limits. As a consequence highly specialized animals are less versatile and have less power of adopting new habits. Within a limited sphere they are more efficient in a struggle for existence, but are incapable of the large modifications that a radical change in environment necessitates. The highly specialized die out when great changes in the environment occur, leaving the less specialized types which alone are capable of enough modification to meet the new situation. There is no connection between the highest representative of one type and the lowest of another. It is the lower and less specialized forms of each that are closely related, and the line of progress to other types is from the less specialized of each type. Use has created many automatic habits, but these have little power of adaptation to new conditions. Perfection in one direction is not the parent of future progress in another. The new develop1 "The Origin of the Fittest," p. 398. 
ment starts from some unspecialized part and follows a path divergent from earlier developments. Use creates energy, but the energy must act on an undifferentiated part capable of development in several directions. Use thus has an effect, but it ends in the elimination of its product. Great cilanges are antagonistic to the specialization that has gone before. We must therefore look to the surplus energy which use creates, and not to its direct effects, when we seek to account for the enduring and uplifting changes in organisms.

\section{SUMMARY}

I. The fact that children do not naturally and cheerfully perform the acts which have become habitual to parents indicates that acquired characters are not directly inherited.

2. If the acquired characters were inherited, the great mass of social customs, habits, and traditions would be unnecessary.

3. Acquired characters secure a better economic support which improves the condition of children. They can now act more naturally than the parents did, and evoke qualities that lay dormant in the parents. Acquired characters also increase energy, and the new energy is utilized by a movement into a new environment.

4. Secondary characters are the natural expression of the surplus energy which the primary characters create. 
5. The order of the change from acquired to natural characters is: first, the production of surplus energy through acquired characters; second, the expression of this energy in the secondary characters; third, the discovery of some use for these secondary characters in which all the species can share, and then the movement of the species into an environment where these secondary characters are necessary and hence primary. 


\section{CHAPTER IV}

\section{EMOTION}

Av environment is natural when the external conditions and the natural impulses harmonize. Acts are then so adjusted to conditions that what is natural is also useful. Yet if the preceding argument is correct, usefulness is a result of naturalness and not its cause. The acquired characters of one environment create surplus energy which evokes new natural characters, and these cause the descendants of those who acquire them to leave the present environment, and enter one where the new characters are advantageous. Usefulness, therefore, follows naturalness, and is the test through which the possibility of permanent natural relations between organisms and environment is determined.

No tendency to leave this natural environment arises, except through the acquisition of a new group of characters creating new energy 
and thus developing new characters that make the relations to existing conditions inharmonious. The being will then seek another environment where its characters will be natural to the situation. But a natural environment will not at first make the need of new characters evident, for harmony breeds content, The tendency, therefore, will be for a static condition to ensue until an increase of numbers brings on a struggle between those whose natural adjustment is so marked that removal is difficult. Struggle is between the adjusted; the non-adjusted are mobile enough to seek other locations or to acquire other habits.

When naturalness and adjustment create static conditions, a new factor enters. Overpopulation causes a deficit which brings about elimination. The force generated by acquired characters is a surplus energy that increases the number of natural characters. In a natural environment it expends itself in struggle, and leads to the elimination of those beings whose energies are not centred upon themselves. There is thus a tendency to reduce the number of characters and to bring the remainder to the 


\section{Emotion}

maximum of efficiency. Elimination does not create characters. It selects them and holds a race or species to its maximum efficiency. It thus causes an economy of structure and energy by means of which the chances of survival are augmented. Economy specializes but does not develop. There is no force in elimination that adds to the number of characters or increases their effectiveness. Elimination thus dwarfs some characters and specializes others. These two effects are the natural results of struggle which must be checked before new characters are developed, and a tendency arises to move into other environments where they are of use, and thus become effective.

This dwarfing of non-essential parts is partly, or perhaps entirely, due to the indirect effects of struggle: it may be with one's own kind, as the struggle between those of a single race, or it may be with other species, as the opposition between the hawk and the birds on which it feeds. On the other hand, the development that increases structure and improves organs springs from the steady, constant relations to the favorable elements in the environment. 
The constant repetition of useful acts creates structure and organs that respond instinctively to the situations for which they are functionally fitted. The sum of constantly favorable elements in the environment fixes the amount of structure and the effectiveness of the organs that can develop in a given situation. There is a tendency for organs to reach this efficiency, and for structure to create instinctive responses to all constant relations between organisms and the environment. Upon the introduction of adverse elements, a less complete adjustment results, or if the more complete adjustment is acquired before the adverse element enters, a retrogression occurs. Organs lose efficiency, and structure disappears, or is dwarfed until a new equilibrium is attained in which the adverse element either becomes a part of the environment or some means is acquired of guarding against it.

To meet this situation, a feeling is generated that in some form is present when struggle with adverse elements is necessary. Instinct is the agent which best utilizes favorable elements, and it grows as these elements become 
constant; emotion is the agent which counters unfavorable elements, and it increases with the violence of the struggle. Instinct acts through structure, while emotion acts against it. If this plain contrast is kept in mind, the simpler acts and feelings may be classified and general laws be stated in a way that will simplify many of the relations between the organs of expression and of action. There is structure which works so mechanically and instinctively that conscious action is unnecessary. Adverse elements cannot create structure; they destroy the necessary favorable relations on which its growth depends, and hence make disadvantageous certain instinctive acts dependent upon it. Adjustment cannot be so close or so constant if there are unfavorable elements in the environment as it could be if they were absent. Structure must become less mechanical, or the mechanical parts must be fewer in number.

When these constant relations develop structure, the direction of the flow of energy becomes fixed. Break up this constant relation by an adverse element, and emotion appears 
which destroys structure and restores the more primitive previous condition. An emotion has no special structure or mechanism for its own expression, but uses structure created for other ends. A laugh is expressed by muscles built for structural ends, and having uses in the processes of adjustment, while a tear comes from a gland originated for other purposes. The muscles which express emotion are merely used in a new way, or in a different combination from that of the instinctive use by which they aid adjustment. A strain upon them may weaken or destroy some of the structural relations that have made them instinctive in action. Emotion, then, destroys or makes a waste which, if repeated, finally ends in throwing the organism back into a more primitive condition with poorer adjustment and fewer organs and mechanisms.

These statements do not differ so much as would at first appear from current views. Professor James tells us that there are "no special brain centres for emotion," 1 which indicates that the emotions start in centres and follow 1 "Psychology," Vol. II., Chap. XXV. 
paths created for other ends. His theory of the emotions is that "the bodily changes follow directly the perception of the exciting fact, and that our feeling of the same changes as they occur is the emotion." If the bodily states did not follow the perception, there would be no feeling beyond the ordinary sensations which accompany perceptions. When bodily changes are felt they create the emotion. This statement of facts harmonizes with my view, but the terms must be made more definite. For "exciting fact" we must put adverse elements, because they alone create emotions. Favorable elements acting through structure seldom come into consciousness with enough force to cause emotion. Emotion is due to the unexpected event that causes a flow of energy in new channels. This outgo of energy is not the emotion, but emotion is its destructive effects upon the mechanical relations that have grown up between the organism and the constant elements of the environment. The vasomotor system, ordinarily involved in carrying off waste products and in replacing devitalized structure, is now excited and its increased 
activity is the main element in the emotion that follows the unexpected discharge of surplus energy.

The voluntary muscles are not strongly affected by emotions. The will has a firm control over them, and hence they are to a less degree the channels along which the unexpected output of energy goes. If they are affected, it is by some sympathetic movement outside of conscious control causing a combination of movements not in harmony with the regular activity of the muscles involved. Herbert Spencer asserts that emotion affects the muscles in an inverse ratio to their mass and to the weight of the parts they have to move. ${ }^{1}$ They act first on the muscles of the voice and face, and gradually extend to the arms, legs, and body. Mantegazza ${ }^{2}$ says they begin in the face and extend to the neck, arms, hands, trunk, and lower limbs. These statements express the general fact that the voluntary muscles, being most under the control of the will, are least affected and come under the

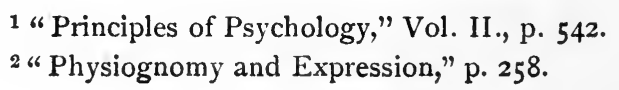


influence of emotion only as it increases in strength. Mantegazza also says that all expression is defensive, ${ }^{1}$ and in another place that emotion is defensive or sympathetic. The two statements are not out of harmony. The defensive expression is the more elementary when the danger affects the individual directly. When an interest in other individuals is acquired, their dangers and suffering arouse sympathy and excite the same or a stronger emotion than if the danger threatened one's own person. Emotion in either case arises from contact with adverse elements, and in its primary effects is destructive of fixed reactions. Ribot $^{2}$ regards the emotions as a case of an arrest of development. The parts of a living being are so closely related that a change in one involves also changes in other parts. Every unexpected action throws a stress on some part not structurally developed to sustain it. The ensuing loss weakens the overtaxed part and leaves relatively stronger other organs whose functions are normal. A change of pro-

1 Loc. cit., p. 82.

2 "Psychology of the Emotions," p. 264. 
portion follows and the organism is modified to meet the situation.

This arrest of development seems to me to be the most important fact relative to the emotions. If the primary effect of emotion is to dwarf structure, it is perhaps the sole cause of the change in organisms when under the stress of struggle. The principle of natural selection assumes that struggle causes starvation and disease whereby the weak are eliminated. If emotion dwarfs and arrests development, the same effects could be brought about much more readily and quickly by it than by natural selection. The dwarfed parts would give new proportions to the body and make it less fit for the existing environment; but by a movement to a new environment, a place could be found where the new qualities and functions would be useful. Emotion thus injures the static, but aids those mobile enough to seek new situations where the new combination of qualities are sources of strength. When deer are attacked by lions, if some were killed the elimination would create change through natural selection. But the emotion caused by the 
attack would act on the living and impel them to alter their habits and also to change their situation and perhaps their food as well. The whole herd would be affected by the emotion and by the arrest of development that follows. A quick adjustment to new conditions would follow long before natural selection would have time to act. It is said that the elimination of the weak would leave the stronger, and thus cause a development in them. But the survivors get an emotion, not a new character. They are modified by it and must shift to a new environment to find a situation natural to their new condition. If the only effects of starvation, disease, or destruction the means through which natural selection acts - were on those killed, we might assume that the survivors were improved. But where disease or starvation kills one, it injures hundreds which live to propagate their kind, and for one animal that a beast of prey seizes, a score are shocked by the incident and live on with new emotions. Starvation and disease always leave the survivors on a lower level, where they become more emotional. Any great national 
disaster checks progress and leaves a heritage of emotional products that are seldom removed. Facts of this kind are plain enough when human society is under observation. No one would expect an epidemic of small-pox or of cholera to raise the intellectual level of a nation, nor do people seek for famines or social disorder to elevate mankind. The same injury of the living would be observed if the effects of the destruction caused by beasts of prey could be accurately ascertained. In the case of animals we see, not the immediate effect of the first onslaughts, but the slowly wrought adjustment between the weak and the strong. The victims have changed environments many times to avoid death, and the readjustments between their changed organs and their new habitats have often proved advantageous. There may, therefore, be an improvement in the long run, and yet the emotion which arrested development and impelled each change may have been injurious if judged from the standpoint of the present. There would in each case be a dwarfing and a changed relation of parts, and then a growth with these proportions, if the shifting 
of environment proved advantageous. The new animal might be larger than the old, and yet the initial effect of the emotion forcing the change might be dwarfing.

Struggle thus breeds emotion, not strength. Wherever it has long prevailed, emotion is the dominant force in fixing social or animal relations. In an old, established environment, people are not strong, rational, and inventive. The hard-pressed races are emotional. They believe in chance and luck, and their acts are detrimental to their adjustment. The test of the presence of emotion is the irrationality of action. Of acts that are nearly alike in their effects, the one will be done and the other avoided. There is thus a narrowing of voluntary deeds, and marked limits are put on choice and consumption. If these are tests of emotion, all hard-pressed animals show by their acts that they are highly emotional. They narrow their choices, limit the range of their food, and act on arbitrary signs of the presence of enemies or dangers. Instead of being forced down to the limit of population by starvation or disease, they nar- 
row their food or activities and thus bring on an arbitrary elimination that does not make for progress. A stationary condition results, and a type is formed that in animals becomes a fixed species. .

In the creation of a species, two forces are needed: one that shall involve the principle of variation and cause animals to break out of their restraints and to adjust themselves to new conditions; and at the same time a second is needed which cuts off further change and drives them back toward their primitive condition. Progress is due to surplus energy; retrogression or an arrest of development comes from emotions. These two forces account for the changes through which organisms go, and as they act more quickly than natural selection, they are more likely than it is to be the actual causes of organic changes.

In saying that emotions are defensive, sympathetic, and the cause of arrested development, I seem to have overlooked one important class, the sexual emotions. They are pleasurable and do not come from adverse elements in the environment. Although this may be 
readily admitted, yet they are in the same general class with adverse elements. Growth and reproduction are antithetical. Reproduction does not take place while growth is vigorous. There is an arrest of development as soon as reproduction begins. The feelings due to reproduction, although pleasurable, act on the structural and functional parts of the body arising out of external adjustment, just as adverse elements affect them. External adjustment is less complete than it would be if the needs of reproduction did not make themselves felt. Reproduction dwarfs in the same way that the excitement of sudden attacks dwarfs. If sexual emotions are in the long run beneficial, it is through their indirect effects in forcing changes of environments.

\section{SUMMARY}

I. In a natural environment the external conditions and the natural impulses harmonize. Characters arise from increased energy. Beings then seek new environments where their natural impulses have more opportunity to develop and to become useful.

2. Struggle indicates the presence of adverse elements in the environment. Growth is determined by the steady 
favorable relations in the environment. Adverse elements act against structure and throw the organism back into a more simple undifferentiated state.

3. Instinct is the psychic expression of the favorable elements that act through structure. Emotion is a like expression of the unfavorable elements that antagonize growth. Instinct acts through structure and emotion against it.

4. Emotions have no structure or mechanism of their own by which they are expressed. They use structure created for other ends. Emotions are thus primarily destructive, create waste products, and force organisms back to a more primitive state with fewer structural adjustments to the environment.

5. Natural selection assumes that improvement is wrought out by the elimination of the weak. If, however, emotions arrest development, the changes in organisms needed for adjustment can be effected more readily and quickly by them than by natural selection. Struggle breeds emotion, not strength. It lowers the tone and throws beings back into more primitive organic conditions. It cannot, therefore, be the cause of the improvements that are attributed to natural selection. 


\section{CHAPTER V}

\section{Reduction}

In the study of reproduction a process has been observed to which the name "reduction" is given. As a necessary step to the reception of the male germ, the egg before fertilization throws off two small parts called polar bodies. The first of these, according to Professor Weismann, represents the separation from the nucleus of the ovogenetic nuclear substance, and the second is a real division of the cell, by which one-half of the essential elements of the nucleus, called chromosomes, are ejected. The egg is thus made ready for the reception of the sperm, and, through the union, the nucleus is restored to its original number of chromosomes and made capable of independent life.

The formation of polar bodies is evidently a process of cell division observed under conditions incident to reproduction. The question 
naturally arises whether it is a phenomenon of reproduction alone or whether this formation may not be a general characteristic of cell division. The ease with which the stages incident to reproduction may be observed, the simplicity of the conditions, and the interest in the problem naturally make it a startingpoint of these investigations. But what is here true, may also be true of other forms of cell division. Two facts appear that seem to have a general significance. In the first place, the specialization or transformation due to the retention of the egg in the mother organism can be thrown off and the egg brought back to its original state. This is the reason for the emission of the first polar body. ${ }^{1}$ In the second place, there can be an actual division of the egg so that it loses some of the parts necessary for a complete existence. The claim has been made that the egg loses its centrosome by the emission of the second polar body, and that the replacement of this necessary part is made possible by the union with the male germ. A polar body would then be

1 Weismann, "Essays on Heredity," p. 351. 
the centrosome of an earlier division retained by the tension of the envelope. If there were no envelope, the separation of the polar body from the reorganized cell would quickly take place and the new cell would have all the characters of the old, and its general or unspecialized powers. But where growth dominates over reproduction, the envelope receives a relatively large share of the nutriment, and is thus enabled to exert a greater pressure on the contents of the cell. Its internal changes are retarded or prevented, and the polar body is held captive until some change permits its escape. When the period of reproduction arrives, growth is no longer dominant and the envelope is relatively weaker than the forces making for reproduction. The egg before the emission of the polar bodies has gone through some of the changes that all somatic cells undergo. In retracing its steps, it throws off its epigenetic development and comes back to its original state. If other cells could be put through the same process, they would in a like manner throw off their complexities and be regenerated. Of this there 
are many instances, for regeneration is a common phenomenon among lower animals, and is in some degree found in all organisms. When an animal replaces a lost limb, a process of reduction takes place by which the cells adjoining the lost part are brought back to the degree of simplicity of the original cells before the growth of the part began. Reduction always precedes regeneration. If the changes in the cells which create the new part could be observed, reductions would be found similar to those that take place when polar bodies are expelled. In reproduction, cells are simplified by the throwing off of polar bodies, and subsequently their natural growth re-creates the lost part. Reproduction and the regeneration of lost parts are not different processes, but spring from the same forces acting under slightly different conditions.

Carrying this reasoning a step farther, another group of facts may be correlated with those just given. Emotions are the psychic expression of certain bodily changes, and represent the effects on organisms of the perception of adverse elements in the environ- 
ment. Emotions are adverse to specialization and their first effects are destructive to the parts affected. If they are adverse to growth, they tend, by weakening the vegetative forces, to favor those that end in reproduction. This thought leads me to assume that reduction is the physiologic expression of facts, the psychic expression of which is emotion; in other words if the psychic feeling could be measured when a reduction takes place, it would appear in consciousness as an emotion, and if the physiologic changes that accompany emotions could be observed, they would be found to be reductions. To put the same facts in still another way, emotions and reductions are both due to shocks which disturb the rhythm of organisms, and, in their disturbance, the specialized parts suffer most and are often severed from the organism and ejected as polar bodies.

These facts are difficult to verify because the reductions that can be readily observed are in simple organisms of whose psychic states we know little, while the emotions we could measure are in beings so complex that 
reductions, if they do occur there, would be hard to locate. And yet the two are not different in kind; moreover if they are both antagonistic to growth, they might find expression by the same means. The emotions have no organs; the currents they excite move over routes created for other ends, and if so, the effects must also be such as other causes create. It seems likely, therefore, that the emotions would use the nerves as a means of dispersion and then induce changes in the parts affected like those that would happen if growth were retarded or the envelope were weakened. The first effects of an emotion, then, would be a reduction ending in an expulsion of polar bodies and the reduction of the cells to a simple condition. Being less somatic they are now capable of fresh growth or of such changes as the new conditions demand. Regeneration follows reduction, causing a fresh growth of the organism in some new direction. This new growth is determined by the forces then active, and it is more or less, as a greater or smaller part of the existing nutriment is set aside for this 
end. The part may be dwarfed or it may be enlarged, but it will at least be altered. Emotion is thus a cause of bodily change, and after each strong emotion, some organs being reduced and others enlarged, the transitions are made by which organisms pass from one stage of their development to another.

In lower organisms, the emotion and reduction due to the loss of an organ are often followed by its regeneration, and the limb or part is soon replaced. Apparently this does not take place in higher organisms, but the difference is only apparent. If we assume that a reduction, by which the specialization of the part is thrown off and the cells are restored to their original undifferentiated state, precedes the regeneration, it follows that this reduction would not take place unless an emotion or shock affects the part that is regenerated. This would be true of lower organisms, for the parts are semi-independent and the response to an injury is direct. But in higher organisms the injury is in one part and the emotion is in another. If a man loses a finger, the emotion is not in it, but 
in his nervous system or in parts closely related to it. The reduction would take place in the part affected by the emotion and not in the injured part. The regeneration that follows the reduction would also be in the part affected by the emotion and not in the part injured. There would, therefore, be no tendency to replace a lost limb, because in its region there would be no reduction on which the regeneration depends.

The separation of the injury from the reduction and regeneration may be even greater. The injury may affect one being and the emotion affect others. The person involved may die and yet the emotional effect be perpetuated by those who saw or heard of the injury, and in them the reduction and regeneration takes place. A shocking accident or a catastrophe may affect the whole community and modify thousands that were not in the least concerned in it. Suppose again that a beast of prey attacks a herd of deer and kills some of them. The emotional effects are in those who escape, and not in those captured, and the changes in them due to their 
emotions are a part of the reactions of their descendants. The reduction and regeneration incident to the emotions may thus be far removed from the parts injured or even from the beings injured or destroyed. If this be true, regeneration may be a universal characteristic of higher, as well as of lower, organisms. The regeneration observed in lower organisms shows what takes place in the higher organisms in the parts affected by their emotions. Emotion, reduction, and regeneration are parts of one process and may be expected to appear in conjunction.

Let us return to elementary assumptions where the simplicity of the position becomes evident. Cells tend to divide by the formation of two centrosomes at which activity is centred. This creates a rhythm, each centre being active while the other rests. A complete division of the cell and the formation of two cells would result, were it not for the strength of the envelope which holds the two parts together. Inside the envelope repeated cell division takes place, but as the organism is bilateral, the original rhythm is perpetuated 
and the movements of the organism correlated. A germ cell, while confined in the ovary, is under the same influences as are the somatic cells. It is, however, in a position to be more easily severed from the mother organism and to go more readily through the changes that an independent organism demands. If severe shocks or injuries throw off some essential part, the reduction through the expulsion of polar bodies prepares the way for its regeneration. The cutting off of the more specialized parts of a cell involves the simplification and regeneration of the remainder. Regeneration is the power of a part to become a whole; but the specialization must be lost before fresh growth is possible. This may happen not only in simple organisms where the shock or emotion affects the parts injured, but also in complex organisms where the shock is carried along by the nervous system and not through the somatic cells. In the latter case, however, the shock is felt in parts of the body distant from the seat of injury. These, then, would be the parts affected by the emotion, 
and in them the reduction and regeneration takes place. Or, again, the result may be even more complex. The reduction may be in the part affected by the emotion, while the regeneration or its equivalent takes place in still other parts. When, in the process of regeneration, the cells strive by growth to replace what has been lost, they must compete for nutriment with the cells in other parts of the body. If these other cells are more active or better situated, they will secure the nutriment and the part affected by the emotion will remain dwarfed. Organs lost or injured by shocks may not be replaced. This will account for the different stages in embryo growth and for the many changes in relative size of organisms after birth. With the development of a nervous organization, such changes must be more numerous and alter fundamentally the characters and activities of animals. The primary rhythm continues, but the somatic cells are aggregated more firmly around the nerves and are capable of sustaining the shocks which the nerves propagate. The parts with few or no nerves are more affected by the shocks 
that disturb the rhythm of the body than are those areas with more nerves. They are therefore cut off or reduced in size by the nervous shocks. The form of the organism is more and more determined by the position of its nerves, for every development in the nerves modifies some parts of the organism by its processes, and injures other parts by the shocks which the older parts are least able to withstand. The development of nerves thus induces both positive and negative changes and renders organisms progressive as long as new nutrition gives the growth that produces, first, folds, and secondly, the necessary new nerves.

\section{SUMMARY}

I. Reduction is a phenomenon of sexual reproduction. Two polar bodies are in succession separated from the female germ cell to make it ready for the reception of the male germ. Reduction is a movement towards simplicity which goes so far that some elements are cast out that must be replaced before growth is renewed. This simplification may be peculiar to sexual reproduction, but there are indications that it is an example of the way in which all tissue is brought back to simple conditions. 
2. Emotion is the subjective expression of that which antagonizes structure and reduces organisms to simpler terms. It may be that reduction is the objective expression of these facts and that it takes place in all organisms subject to emotional states. Reduction in this case would precede regeneration and be the natural step by which organisms lose forms of specialization no longer of use, and receive in their place other forms of present advantage.

3. Reproduction and regeneration are not different processes, but are due to the same forces acting under different conditions. Emotion is the same force expressed as feeling, and in conscious beings is the index of the despecialization and regeneration acting within them.

4. In lower organisms the emotion, reduction, and regeneration take place in the same part, and a lost limb is often restored; but in higher organisms a reduction may happen in one part and the emotion be felt in another. The regeneration then follows the emotion; the despecialized part is not restored, but a new specialization begins in the part affected by the emotion, and a new organ is formed or the relation of different organs is altered. The emotion may also be felt by beings not concerned in the reduction, as when a man sees an accident; then the emotional changes and the regenerative processes affect the observer and not the injured person. Emotion, reduction, and regeneration are parts of one process and may always be expected to appear in conjunction. 


\section{CHAPTER VI}

\section{Responsiveness}

THE principles already presented deserve consideration as secondary laws. Precedence has been given to present facts, among which those readily accessible were preferred. Proof should move from the obvious to the obscure, from the present to the past, from the known to the unknown, from concrete instances to inferred generalizations, and from the external to the internal. The present, the known, the concrete, and the observed should give a body of secondary laws, and these, through reflection, deduction, unification, and generalization, may be transformed into primary laws. If what has been said has a surface correctness, the results deserve notice, and if the plan is correct, they should be capable of restatement in more fundamental forms.

The general result alone needs restatement, for it is the sole basis of what follows. The 
source of growth and change is internal, not external. Growth is caused by nutrition resulting in surplus energy, and not by the external objects with which contact is necessary and through which survival is finally secured. It forces organisms into natural environments where harmony with their surroundings is possible and helpful. Internal changes are felt and appreciated before the modified being finds a place where they are useful and effective. Consciousness thus precedes use and is neither an effect nor a consequence of it. The voluntary act antedates the involuntary; instincts and habits follow rather than go before the less definite impulses which do not depend on structure and specialization. Movement precedes growth, and structure arises before it finds a useful function. Were men guided by their current observations, discarding both theories and complex analyses, they would find plenty of proof for these assertions. A microscope or a bold deduction might prove much of it to be defective, but in some way the more fundamental laws would be the expression of current observations. The facts of everyday 
life may assume a radically different form in scientific laws, and yet they are there. The primary laws confirm the secondary if the latter are really the result of observation.

Opposed to these observations is the theory that the mind is a blank until aroused by external sensations. Nothing but the physical and material can exist until contact with the external starts mental activity. Therefore consciousness can play no part in the formation of ultimate organic relations, but is a result that appears after they have been established.

This philosophy, attributable in the first instance to Locke, has been thoroughly ingrafted on modern thought. It holds sensation to be primary and the only basis upon which the higher faculties rest. The starting-point of consciousness is assumed to be the external stimulus which comes over developed nerves, and not a result of the general conditions of life. We now know, as Locke did not, that all the elements of consciousness exist in various combinations in the cell before the nerves appear. We know that even the simple nervous arc which gives sensation and its motor response 
is not the first form of activity. Movement precedes the structure which makes sensation possible. When an efferent nerve carries a current from the surface of the body to a nervous centre and then a return current passing over an efferent nerve causes bodily movements, we have the simplest form of reaction between organisms and the environment, but nevertheless it may not be the simplest form of mental activity. If, instead of starting from nerve centres, a start is made from the principles of cell growth, a different aspect of simple conditions is attained, for life may be unicellular in which no nervous response is possible. After multicellular organisms appear it is some time before a distinct nervous system arises. The simple in mental life must therefore lie in cell structure, and not in the more developed reactions which the nervous arc permits.

It is a well-established fact that the highest form of cell is the original germ cell from which all others are derived. In it are all the qualities which the later-developed cells reproduce, each in its own realm. The responsiveness of this germ cell to general stimuli 
is also greater than that of the somatic cells, which, being more specialized, respond only to particular agents. If the germ cell alone has the capacity to respond to every stimulus, it alone can be the seat or the necessary accompaniment of consciousness. Objectively considered, consciousness is responsiveness, and responsiveness must be either cellular or intercellular. The intercellular parts are less responsive to general stimuli than the cells, and the somatic ${ }^{1}$ or derived cells are less responsive than the original germ cell. Its continuity alone is preserved in reproduction, and it is all that the different organisms have in common. Consciousness, the common quality of all life, would seem, therefore, to be connected with this unique germ cell, and any objective method of measuring it through responsiveness must join the two together and regard them as two sides of one function.

If this is so, the simplest forms of consciousness should coincide with the simplest form of

${ }^{1}$ Somatic cells are derived by differentiation from the original germ cells. 
growth. ${ }^{1}$ As soon as cells divide and differentiate, the manifestations of consciousness should appear in connection with this growth. Any aggregate of cells that becomes structure should be the means of making more definite the two elementary functions, movement and consciousness. This would be true if the outward current through any structure should create movement and the return current should arouse memory, the simplest element in consciousness. If a structure permitted an outward flow that appears objectively as motion, no additional mechanism would be needed for a return flow which should affect the germ cell and so excite thought. When the outgoing and incoming currents traverse the same structure, the effects of the current from the germ cell to the somatic cells is movement, and those of the current from the somatic to the germ cell is memory. When the outgoing and incoming currents utilize different structure, the one is motor and the other is sensory. Sensation comes, therefore, at a later stage of development than memory, and demands a

1 I use "growth" in the sense of the multiplication of cells. 
more complex mechanism. Any group of cells, by making structure, can yield movement and memory. They are the necessary accompaniments of all multicellular growth. But sensation demands the nervous arc, and this appears only in a more complex form of structure.

The growth and changes in cells have two processes: the period of growth during which energy is stored - the anabolic; and the period of change, waste, and destruction of the stored material - the katabolic. Which of these is the cause or accompaniment of consciousness? It cannot be the anabolic process, because that is particularly active during sleep, when consciousness disappears. Besides, we know that thoughit processes are accompanied by destructive changes through which waste products are formed. This means that consciousness is confined to katabolic epochs and is continuous only as katabolic changes are continuous. We might therefore expect a simple cell to have a conscious period during the time of katabolic destruction and a lapse of consciousness when the anabolic processes were building up the cell. An intermittent consciousness 
would first result - an evil, however, which would be removed by the development of two centres of katabolic activity. Each in turn would sustain consciousness while the other underwent anabolic changes. Consciousness would thus be a rhythm, a movement, and a destruction appearing in turn at two centres. There would be a rise of consciousness as each centre increased its activity and then a decline in consciousness until the increase of activity at the other centre again raised its level. The struggle for the continuity of consciousness would then consist in having these two centres so alternate in their activity that a given level is maintained.

This condition creates an evil almost fatal to a continuous consciousness. The two centres of activity, in becoming habitual, tend to create cell division, and two cells are soon formed, in each of which there is only one active centre, so that new centres must be formed to maintain the rhythm demanded by a continuous consciousness; and when developed they again divide the cell and destroy the continuity. Such are the endless attempts to reach a con- 
tinuity of consciousness without any enduring success. Only one way out of this difficulty is apparent - a growth in the envelope of the cell elastic and strong enough to prevent complete separation of the divided cell. Multicellular organisms then appear which preserve all the characteristics of the unicellular activity, - continuous rhythm and growth in two balanced parts. Any disturbance of the equilibrium proves destructive of the organism and each half corresponds to the other, both as a whole and in its parts. Every movement in one part is followed by a rest and an activity in the other part. Movements may be said to be katabolic changes in the germ cell affecting the somatic cells, while memory is the effect on the germ cell of katabolic changes in the somatic cells. The more important the latter becomes, the less is the stress on the original cell, which if too frequent or strong, would by disrupting it end life. The development of instinctive responses in the somatic cells which follow nervous growth also relieves the original cell without interfering with the continuity of consciousness. Memories now become the leading 
states of consciousness, and activity is in the main transferred to other centres, so that less damage is done to the organism by the vigor of their activity. In this way complex organisms are developed that comply with the demands for rhythm and harmony, and also raise memory into a dominant psychic trait.

I have in the foregoing pages presented the consequences that flow from a few simple assumptions; first, a difference between the germ cell and somatic cells by which the latter become structure and the former exhibit responsiveness; second, a relation between movement and memory so that one structure can excite both memory and movement simply by a change in the direction of the nervous current; and finally there is the assumption that consciousness is confined to katabolic epochs. As these are intermittent, two centres of activity are necessary to form a continuous consciousness. A rhythm of action follows, resulting in the growth of complex organisms with all those diverse elements and conditions which puzzle the observer.

Many simple facts harmonize with these 
assumptions. Organisms are bilateral. The parts of the brain are duplicated and the right and left sides of the body are similar. Bodily actions are in rhythms which, by being pleasurable, help to sustain life, while any movement out of rhythm is painful and destructive. Many philosophers make rhythm a fundamental law of the universe, but even without such an extensive application, the validity of the thought may easily be verified in organic processes. The love of music, the harmony of colors, and the constant desire to replace each sensation, feeling, or emotion by others, all indicate how important this principle is. If it is not a condition of life, it is at least an important secondary law and in this form it will serve my purpose.

Professor Weismann has made emphatic the difference between the germ cell and the somatic cells derived from it. Although the germ cell can influence the somatic cells, yet they, in turn, cannot alter its structure. It retains its full responsiveness and hence can reflect in itself the essence of the changes in the somatic cells. It has, therefore, the condi- 
tions of consciousness and more readily may be assumed to be the seat of consciousness than any other part of the body. In fact, by a process of exclusion it would seem to be the only possible seat of consciousness, because the necessary specialization of the somatic cells takes from them the general responsiveness needed for a continuous consciousness. Nor could the rhythm of the body be established unless it began at the first division of the germ cell through which the organism developed. If rhythms are the only means of sustaining consciousness, they would of necessity be a function of the original germ cell and must continue in connection with it. The rhythm of the germ cell creates structure in the somatic cells, and the movements resulting from this structure excite a nonstructural response in the germ cell. Movement thus builds structure, and structure, in its reaction, excites memory.

The fact of cell division also strengthens the belief that consciousness is sustained at two centres in the germ cell. Each cell has a centrosome which appears to be its dynamic 
centre, and which divides when a new cell is formed. At any rate, the first indication of cell division is the appearance of two new centrosomes about which the activity of each part is concentrated, and, as they grow, the cell is gradually divided until each part becomes independent. Two new centrosomes now appear in each new cell and the process of division is repeated. If consciousness is evoked by the activity of these centrosomes and two centres of alternate activity are needed to sustain it, the process of cell division must be delayed so that segments instead of new cells may be formed. This is done through improvements in the cell wall, by which it becomes more elastic or stronger and thus prevents the alternate activity at the two centres from completely severing the cell. If subsequent division likewise fails to break through the original cell wall, the aggregate of cells forms a multicellular organism. The simplest of these aggregates involves a bilateral growth in which are all the elements of a continuous consciousness. Each of the two original centres controls the activity of its 
part and the reaction of the subordinate or somatic cells is the antecedent of memory. Sensations due to outward contact have to wait for a more complex organization to separate the route travelled by the outgoing and incoming currents. So long as they moved over the same route in alternation, no outer object can be distinctly perceived nor can the use of organs determine their growth and development. Adjustment would be accidental.

An aggregate of cells therefore indicates conscious action, in that the secondary cells, or segments, respond to the impulse of the mother cell. It also indicates memory since the activity of each part repeats the activity of the other. While one half is active because of an outgoing current in its direction, there is an ingoing current from the other half, each part being directed in its activity by what has taken place in the other. This is the essence of memory - the reproduction in a new activity of that which has been done before. In a simple bilateral organism there must always be a memory present to guide each new activity, because the other part has just 
done the act that is to be repeated and its effects still remain in consciousness. Either side is the mind when the other is the moving body.

\section{SUMMARY}

I. The highest form of cell life is in the original germ cell. The responsiveness of this cell is greater than that of any of the somatic cells derived from it. It must therefore be thought of as the seat or necessary accompaniment of consciousness.

2. The simplest form of consciousness should coincide with the simplest form of cell growth. Consciousness and movement are opposing poles of the same forces. Outgoing currents through cell structure create movement; ingoing currents arouse consciousness. A group of cells making structure can yield movement and memory.

3. In growth anabolic and katabolic epochs alternate. Consciousness is confined to the katabolic or destructive epochs. It is therefore naturally intermittent and can be made constant only by a doubling of the katabolic centres so that one may sustain consciousness when the other rests.

4. Consciousness is a rhythm between two centres. Two active centres tend to disrupt the cell, and for this evil the only remedy is the strengthening of the cell wall to resist the disrupting tendencies.

5. The presence of two active centres, while the cell divides, tends to confirm the foregoing analysis of consciousness. 


\section{CHAPTER VII}

\section{Sensation}

Adjustment is a process, not of creating the conditions of consciousness, but of getting a content for it. The original cell has all the responsiveness of any cell, but this capacity cannot be made effective until a structure has been developed that conveys to it some indications of the external world. The first struggle, however, is not for experience, but for consciousness. If consciousness coincides with katabolic changes, and two centres of activity are necessary for its continuity, certain elementary relations must be worked out before sensations can be received and interpreted. The tendency for cells to subdivide starts a development in the envelope, and causes the growth of structure to be bilateral. This preadjustment stage of development can be measured subjectively by consciousness, pleasure, and memory; and objectively in rhythm, mo- 
tion, and structure. All these are present in the simplest forms of multicellular life, rhythm being the objective expression of a continuous consciousness. Motion is likewise the objective expression of pleasure, and structure is a like expression of memory. Such an organism could perpetuate itself so far as its own conditions were concerned, but it would be at the mercy of any adverse objective change. Without sensations, no adjustment and no avoidance of external evils are possible. As soon as the interests of different organisms come into conflict, the acquisition and development of sensations begin; but they must develop along the lines of the struggle for consciousness, and utilize the material it furnishes. All the elementary forces are already in play. The problem is to use them to secure a content, as well as a continuity, for consciousness.

To show how this is wrought, I will again say that all structure is the result of motion, and that simple structure directly subserves the subjective end of sustaining consciousness, and indirectly, the objective end of creating movements. The struggle for consciousness 
involves the development of motor organs. Structure not needed to sustain activity can serve, by becoming passive, as a channel for currents excited by external relations, and convey to the mind indications of what takes place on the outside. Sensation, under these conditions, is the utilization of disused motor organs for the purpose of receiving impressions. ${ }^{1}$ Disused parts acquire a new use by forwarding currents inward. Before this differentiation survival is purely accidental; after it, the environment acts on organisms, and gives an advantage to the best developed. The external now becomes known, and the better movements of the more developed organs assist in adjustment or in the avoidance of evils. A new epoch of development is entered, in which consciousness is sustained by the continuous inflow of impressions instead of the early dependence on the spontaneous activity of the germ cell.

Let us picture this change on the organic

${ }^{1}$ See the writer's article on "Overnutrition and its Social Consequences" in the Annals of the American Academy of Political and Social Science, July, 1897. 
side in the way it may occur. The elementary form of cell growth is an aggregate extending in two directions from the partially divided germ cell, each part duplicating the other. If these two parts do not have equal growth, one will overreach the other. This overreaching produces a fold, and a fold has the possibilities of an ovary. The surplus energy of the original cell does not now go out to so complete a degree in the formation of somatic cells, but a bud is formed with all the qualities of the original cell. It tends to pass out through the enclosure and become an independent organism. But to get out, it must break through the envelope that encloses the cells. If it succeeds, then new organisms result; but if the envelope is too strong or elastic, this series of enclosed cells becomes nerves. Nerves are to be thought of as motor organs made passive because the germ cells from which they are derived cannot get the outer position on which movement and more complete growth depend. They thus have new functions forced on them in harmony with the organism within which they are enclosed. Being more responsive to 
stimuli than are the somatic cells, they carry stimuli more easily and with less waste than earlier growths. Nerve cells are germ cells captured and turned to a new use. Their differentiation is not due to the simple laws of growth, but is the result of the pressure of complex conditions. Were they free to assume simpler forms, they would become independent organisms instead of mere propagators of activity generated elsewhere. Their passivity is not a natural state, but is impressed upon them by confinement. All cell aggregates are primarily motor. They lose this function only in an abnormal position.

Herbert Spencer has said that the growth of nervous power is opposed to reproduction, and that the rate of production falls off as nervous power increases. If the nerves are made up of germ cells, the greater part of which are retained and specialized, the organism has less surplus energy to reproduce its kind. Confined sex products thus become the means by which currents are propagated. They are more responsive and quicker conductors than other cells, and motor energy passes along 
them more readily than over other mediums. Nerve cells are thus germ cells which, in simpler organisms, would have become independent beings. Wherever growth is active, it absorbs the greater part of the nutrition that the organism assimilates. Folds are formed, and their growth develops enclosures before the buds have time to develop, ripen, and escape. There is an opposition between growth and reproduction. Where growth is rapid, buds do not push out rapidly enough to prevent the growing folds from reaching and enclosing them by a fusion of the edges. Reproduction is thereby delayed, and its amount is much reduced below what it would be if the earlier sex products were not confined and transformed into nerves.

If this thought is in a measure correct, form is given to organisms through nerve growth. Mere flesh would be little more than a mass. Nerves grow in fixed directions and press against the envelope that holds them in. Being sex products, they strive to break through the envelope and free themselves. They succeed if the envelope is not elastic, or 
if the growth is so slow that the envelope cannot adjust itself to the new conditions. But where growth is active, the envelope yields before the growing nerve, until an equilibrium is attained, with the result that a new organ is formed. In case a partial break in the envelope is made, renewed growth, finally gaining the upper hand, keeps the nerve encased in the envelope. A tooth seems to me to have such an origin. The nerve, in its effort to emit its sex products, presses against the skin and partially breaks through. The skin hardens over the injured part and the tooth results, which holds the nerve in. The troubles of children in teething are due to the conflict of the nerve forces and the growth forces. In the end the latter conquer, and then an equilibrium is attained with a passive nerve.

On the face of things, this may seem an inadequate explanation, because teeth appear to come because they are useful, and the result of adjustment rather than a mere effort of sex products to free themselves. But it should be remembered that teeth in lower organisms are not necessarily useful organs. They often 
appear in great abundance in places where they have no function. Evolution eliminates the useless teeth and makes those that remain more useful. A mere struggle between growth and reproduction could thus cause the beginnings of teeth and permit selection so to operate that they would be converted into useful organs.

A nerve, from this viewpoint, is a series of sex products so enclosed within an envelope that it cannot break out. In the plant the flower that reproduces is at the end of a stem, and becomes a sex organ if it gets the mastery over growth. The brain and the spinal cord may be thought of in the same category as a stem and flower, only the brain never succeeds in forcing its way through the envelope that encloses it. It is a sex organ that never attains its elementary functions. It would be even better to think of it as a loosely organized colony subdividing and trying to give off sex products, but prevented by the encasement that checks division. Failing in its original purpose, it becomes an organ of sense discrimination and serves as a centre of nervous currents moving to and fro along the spinal cord. If 
consciousness depends on responsiveness, the undifferentiated cell would be most capable of it. No cell can be less specialized than the germ cell, from which all others originate. If the brain is a sex organ,-an enclosed ovary capable of creating sex products, - it would have undifferentiated cells that might become the seat of consciousness. Keep this loose colony of germ cells from separating, and the grouping of cells necessary to a vivid consciousness would result.

Sensation is, then, not a simple state of consciousness, but the product of numerous complex conditions. The organism must attain considerable complexity before it becomes cognizant of the external world. And yet these conditions fall back on a few simple ones that are easily perceived if the complex conditions of survival are eliminated. If survival is the ultimate condition and starting-point of life, then life is complex and hard to explain. But if mere continuity is the first end, its laws are plain. There must be a rhythm of action due to katabolic changes, and the envelope must develop to resist the tendencies to disruption 
These two conditions involve all the others. Sensation is the final result of the first stage of development, and the beginning of a new epoch in which external conditions have a dominant place. It is thus the beginning or the end, just as the emphasis is placed on life or on survival.

If this be so, the two parts of my argument agree. The problem is, How is the surplus energy of improved economic conditions utilized to make permanent changes in organisms and to allow the effects of economic betterments to perpetuate themselves? The reply in terms of biology is that increased nutrition results in a larger number of somatic cells, the unequal growth of which causes folds which are centres of reproduction. The germs created in these incipient ovaries are cast off if the rapidity of growth does not cause them to be enclosed and retained as parts of the organism. They are then transformed into nerves which are better channels for nervous currents than are somatic cells. So long as growth is dominant, the number of folds increases, bringing with them a more 
complex system of nerves and the concentrated control of higher organisms. New nutrition having augmented the number of folds, and forced the increased complexity of the organism, now raises the level of its psychic life.

These changes are associated with use when use is spoken of as the cause of development. Judged by effects, there is a measure of truth in the claim, but it should be remembered that the organism is altered and new organs or parts are created, not because they are of use, but as a result of the way new nutrition acts on the organism. The law is an expression of growth and not of survival. When, however, an organ is formed or a part is modified, the organism is out of harmony with its old environment and must seek another where its new powers are of use. When a new equilibrium is attained, the harmony between the organism and the environment indicates that the environment was the cause of the now useful organs. But this is not true, for, as we have seen, they are the result of the surplus energy of a preceding environment which so interrupted the harmony 
between the environment and the organism that it was forced to seek a new adjustment. Use follows growth instead of preceding it, as current doctrines assert.

So much for one side of the problem; on the other side the dwarfing or disappearance of organs must be accounted for. And now we must look to the emotions. The shocks to the system reduce the parts affected by the discordant nervous discharges, and they are thrown back into their earlier state to grow again, if they are to be re-formed. Regeneration is usually possible, although growth may be inconsiderable if other parts of the system are making urgent demands for fresh nutrition. Organs disappear or are much dwarfed, while the new parts grow and absorb the unappropriated nutriment. The discordant shocks affect the parts least supplied with nerves, and trim them down. The nerves have direction, and give form to the organism by the gradual reduction of parts without them.

The reduction and alterations made by these forces transform beings, and cause organs to disappear or to be modified. To them must 
be attributed the changes that are commonly attributed to disuse. Not in disuse, however, will we find the source of changes that cut down organs. Useless organs might remain indefinitely if the emotions did not affect them disadvantageously. But when cut down by nervous shocks, they do not grow again to their full size, if other parts absorb the nutriment on which growth depends. If this be true, the apparent effects of disuse are easily accounted for without assuming that acquired characters have any effect on the descendants of those who acquire them. The play of the emotions is sufficient to account for the reduction and disappearance of organs.

\section{SUMMARY}

The original germ cell has a capacity for consciousness, but no content. For a content structure is necessary, through which will and memory are evoked. Sensation is not, therefore, an elementary function of consciousness, but an imposed condition, and presupposes the existence of nerves, which, in turn, are the complex resultant of several conditions. Growth creates folds and they become incipient ovaries, the sex products of which are nerve cells. These cells are enclosed germ cells so differentiated and united 
that they are ready means of passing motor currents. When, through more extensive differentiations, some of these motor segments are of no further use in movement, they become feelers which direct inward impressions from without. These impressions are sensations and become important aids to survival. 


\section{CHAPTER VIII}

\section{Visualization}

THE popular concept of the mind emphasizes the conditions of survival instead of those of life. The outer world, from which sensations come, gains its importance through the struggles for its possession. As these struggles become more intense, consciousness is more fully centred on outer events, until, in the end, the sensations by which we know such events seem the sole content of the mind. Consciousness, then, appears to begin with the quality which gives superiority in struggle; but life antedates this struggle and its elements must in some way have already existed in the simple conditions upon which life depends. Struggle creates nothing; it only gives clearness and value to what had another origin. Nor is it an advance to analyze the contents of consciousness into simpler elements of a like kind, - if progress is to be made, let us find the physical 
accompaniment of each mental phenomenon. Have not memory, will, sensation, and other psychic contrasts a physical background, and are they not at bottom distinct or similar only so far as they have the same or different physical antecedents? Psychic effects cannot be more complex than their physical causes. When, therefore, we know the deeds the body can do, we know the psychic variety the mind can manifest. Any greater complexity is not real but apparent.

In the simplest form of life, the surplus energy due to assimilation creates more cells and greater complexity of form. This natural growth is bilateral, and action due to surplus energy is rhythmic. There is a rising tide of activity on one side when there is a falling tide on the other. The conscious effect of the latter is memory, and that of the former is will. There are not in structure a storehouse for memories and a distinct mechanism to start bodily movements. When we see the antecedents of a movement and not its consequents, we call them will; when we are conscious of the consequents and not of 
the antecedents, we call them memory. Interrupt rhythms and destroy all bilateral relations and memory ceases. I say again, memory is not a storehouse; nor is it concentrated in the brain or elsewhere, for it is the fibre and warp of the body. The only record of the past is in some growth which changes the direction of nervous currents and of activity. Memory is, therefore, a phenomenon of related parts. Isolate these parts, break up the correlation of structure that makes rhythm, and the resultant activity is visualization, or the struggle of a part for its natural complement. A physical deprivation becomes a mental picture inciting to activity. In isolation the complementary unknown looms as more than real. The mental picture is not a fact, but a fancy, and in the channel it forms there is a pleasant flow of energy so long as the surplus vitality holds out. This, in its simplest form, is the sex impulse, and the irritation of sex isolation is the prime motive in the struggles for the realization of fancy. Separation raises the level of consciousness and intensifies its pictures. Strongest emo- 
tions are for ideals which complement the onesidedness of reality, - we repeat in each such picture the isolation of the sex impulse, and each rising tide of idealization indicates some lack of complementary unity in the physical background of thought. A physical break precedes the mental elation which accompanies visualization. It is simple katabolic activity in a disrupted, despecialized cell, and is thus an upheaval, - an emotion, - a want of equilibrium which ceases when the physical equilibrium is restored. An intense consciousness means some physical rupture in the forces that make for life and growth. Let me put this in its simplest form. Bilateral growth is a primary tendency of life in which action is rhythmic. Isolate these parts and each tries to replace the other by regeneration. There is a physical impulse inherent in organic life that struggles to restore any disturbed equilibrium. If thought and life run parallel, this physical impulse which demands and shapes the physical complements of an isolated part, must have a mental accompaniment that points a complement to the ideas which this part can 
itself create. The mental struggle for complementary ideas is visualization. It might be called the strain of an interrupted rhythm. Ideals are the result of a struggle for mental regeneration, and they appear when a break in continuity arouses an impulse to establish physical complements.

Visualization and memory are now seen to represent opposing tendencies. Wherever there is growth there is memory: visualization comes with disruption and tendencies toward simplicity. The isolation of parts naturally rhythmic creates a sudden burst of activity, and this intensifies mental life. Memory is dimmed and consciousness projects pictures of lost complementary relations. Whenever there is a break in growth, the current of thought flows on some absent relation, and then the thought becomes fancy and not fact. These breaks come through the emotions, and they represent the discordant elements that disturb growth and throw life back into simpler forms.

The three elementary mental states coincide with three physical conditions. Memory accompanies bilateral growth; emotion arises 
when discordant elements interfere with this harmonious growth, renewing it in a simpler form; visualization springs from the isolation of parts by disruptive elements. Start growth and memory will appear. Arrest it, and emotion arises. Struggle to reconstruct it and visualization begins. A disruptive discharge of energy is emotion, a blocked discharge is visualization, while a harmonious discharge is the source of memory. A developing organism with plenty of surplus energy has periods of growth which create the structure upon which will and memory depend ; it has disruptive epochs when some portions of this structure are destroyed, simplified, or isolated, and epochs of regeneration when growth in new forms builds new structure which conforms to new needs.

Emotion and visualization are the result of these periods of transition. If structure becomes hardened so that it does not change, the qualities disappear or are much weakened. It is natural, however, that structure should be displaced and new forms, bringing with them new memories and actions, should appear. 
Struggle prevents these processes, retains old structure because its particular form is of use to the organism, and diminishes the nutriment, and therefore the surplus energy, of each competitive organism. The insufficient expenditure of the smaller fund of energy in struggling organisms at length stops the displacement and replacement of structure. But an embryo which has no struggle but plenty of surplus energy builds, tears down, and replaces structure in a hundred ways. The adult uses its diminished fund of energy to repair old useful structure. Energy traversing this old structure is habit, and when it assumes fixed forms like useful recollections, we call them "associated ideas"; but habits and associations are only remnants of mental life in the retained structures, while sensation is visualization dimmed and regulated by passing through these same hardened structures.

When a structure is so hardened that it cannot change, the same product following each excitation enables men to judge accurately of the external world and to increase their chances of survival. Had energy remained abundant and 
no need of struggle appeared, these structures would have been replaced, not repaired, and then habit, association, and sensation would have been less definite and more constantly modified. Life would always be the Present, with new structure to create new thoughts, and new emotions and visualizations to broaden its contents. We think of memories and sensations as being accurate representations of the past, or of outside conditions. But this is true only as they are the products of hardened structures. The being of larger energy makes new structure, and mingles his emotions and visualizations with structural products in the form of memory and of sensation. The more mobile the structure, the more do all these elements melt in the flow of thought and the less able is the thinker to distinguish their origins. In the growing child fact and fancy flow along together - a condition which would remain if new structure were as readily created in the adult as it is in the child. But struggle makes men analytic by forcing them to attend solely to sensations and associated memories. Emotion and fancy are not only isolated but are 
even dismissed as unrealities from the mental products of a more structural nature. They are, however, the prime elements in the broader life displaced by struggle, and no analysis of mental products is possible if it does not begin with them. Memory and visualization are thus at opposite poles of thought. Memory acts through structure and increases in clearness as structure grows in complexity and in the definiteness of its action. Visualization is the acme of isolation. Interrupt complexity, decrease the number of complementary relations, reduce life to its simplest terms, and visualization becomes more intense at each step. It is as simple and vivid as memory is complex and clear. Thought varies between these two poles and has ingredients from both of them. As it rises in intensity, turning toward the complement of the real and present, it becomes ideal, but when it falls in intensity, settling back on the present and real, it becomes grooved in structure as memory. Devolution and growth are thus both represented in thought, and by their relative force fix the direction of its currents. 


\section{SUMMARY}

Memory acts through structure and depends upon its laws. It becomes clear and forceful as structure becomes complex and definite. There is no storehouse for memories. They are not separate accumulations nor centres, but are due to routes through structure made by previous activity.

Stop the correlations of structure, isolate related parts, and the resultant activity is visualization. It is the mental side of the struggle of a part for its natural complement. In its simplest form it is the isolation and struggle of the sex impulse, but in its higher forms, it becomes fancy and gives a background to the idealism of thought. Idealism is the activity of a disrupted despecialized centre. It is the acme of devolutional forces in the same way that memory is the product of evolution, growth, and structure. 


\section{CHAPTER IX}

\section{A Possibility}

IN the foregoing explanation only a few simple elements have been used. Facts about cell life have been correlated with the external conditions upon which life depends, and an endeavor has been made to show how things discovered in one field express themselves in the other. An adverse objective condition, an emotion, and a reduction affecting the cell are the same elements viewed in different ways. Several such parallels have been worked out to furnish an explanation of the simple facts of life and nutrition, without the introduction of unknown quantities or qualities. But even admitting that simple life is fully accounted for in this way, we are still far from a ready explanation of human beings. Either new elements must be admitted or the simple elements are capable of more complex relations than those already pointed out. As most writers think that consciousness is 
not a product of cell activity, there is apparently a gulf between the simplicity of the cell and the complexity of higher life with its concentrated consciousness. Are we then to look for new and foreign elements in the higher life, or have we in some disguise the simple elements we already know? We may at least consider the possibility in the latter query, even though we may be far from proof. There is an attraction in carrying ideas to their legitimate consequences even though they appear there in a somewhat fanciful form. But when the hypothesis is carefully examined, much of its fanciful character disappears. It is not strange that simple elements should produce remarkable effects if they have the time and conditions in which to act, and the theory of evolution leads us to expect that things known in one form might be gradually changed into forms seemingly different and strange.

The facts presented show that the highest form of a cell is the undifferentiated germ cell with which life begins. Greater complexity in the cell and in its relations enables specific 
things to be more easily accomplished, but the gain thus made in particular directions is accompanied by a loss in that general responsiveness upon which consciousness depends. Reduction and regeneration may bring back the responsiveness which the somatic cells have lost, yet if a lack of differentiation is the test of the heights to which cell life can ascend, germ cells would still be the superior cells and those in which consciousness reaches its highest form. We have, however, a tendency against consciousness in the fact that reproduction takes from the body the cells which, if retained, would be the best medium of consciousness. This, in part, is counteracted by the retention of the sex products within the body and their transformation into nerves. But admitting this, nerves are specialized products, and while they permit a freer and readier flow of nerve currents, they do not form the undifferentiated centres where consciousness might dwell. To account for nerves is one thing; to account for a head and brain is another. A body may have instincts, emotions, nerve currents, - yes, 
even memories; but brain action must have some other explanation, or at least some other combination of the elements upon which bodily actions depend.

In this explanation I shall rely on a few simple facts already offered: first, the highest cell is the undifferentiated germ cell; second, where growth dominates over reproduction, germs may be enclosed within the body; and third, the folds created by rapid growth become ovaries, where sex products generate. ${ }^{1}$

1 An ovary may be defined as a place where sex products are confined. If they are due to folds, these folds may be external or internal as the folds open outward or inward. The external ovaries would naturally discharge their products, in which case fertilization by sexual means could take place. But the internal ovaries cannot thus discharge their products. They can at best become buds and gain independence by severing the original organism. Growth by buds may thus be a combination of reproduction and regeneration. The inner part doubles, but the outer part is divided and the missing parts of each portion are regenerated. In the case of the alternation of generations it would seem that in one form the ovary is internal, and the growth is by budding, while in the other the ovary is external and reproduction is sexual. It may also be said that growth by budding is alone possible where growth dominates largely over reproduction. Then all the ovaries become enclosed, and sexual reproduction is impossible until the growth forces are much weakened. There may be many generations of asexual reproduction. 
We may have an enclosed ovary in which the possibilities of germ cells are realized and the phenomena of undifferentiated cells are manifested. My belief is that the brain is an enclosed ovary, with its contents of undifferentiated cells put to a new use, due to their isolation from the other sex elements with which they would normally come in contact. An illustration is found in plants, many of which have male and female flowers so isolated that the female flower is fertilized only by outside agencies carrying the male elements to it. Suppose one of these flowers were enclosed within the plant because growth was so rapid that it could not break through the envelope. There would then be an exposed ovary of one sex and an enclosed ovary of the other sex. If in part of the plants the female ovary and in others the male ovary were enclosed, the exposed or outer ovaries of these two plants could produce germs which, when brought into contact, would lead to reproduction and thus perpetuate the plant. An animal, in my opinion, differs from a plant in this way; it 
106 Heredity and Social Progress

has an enclosed ovary which in its development becomes a head, and an exposed or outside ovary which takes part in reproduction. The head of a female would be male, while the head of a male is female. This origin of the head demands no other elements than those known to exist in the simpler phenomena of cell life.

There is an even less complex hypothesis than this, although it offers fewer analyses to prove it a possible line of development. When, in fertilization, the male element enters the female cell, the two nuclei join into one which may not lose the identity of either. In each the chromosomes have been reduced to half of their normal number, a fact which has been taken to imply that in the union a single nucleus is formed with the proper number of chromosomes, one half coming from the male, and the other from the female. Another interpretation is, however, possible. The reduction in each germ, whereby some of its elements are lost, may have been due to an emotion by which the more specialized parts were thrown off. A regeneration could then make each 
nucleus complete. If the two nuclei, reduced to their lowest terms by the loss of the more specialized parts, unite, they may not merge; each may seek to complete itself through regeneration. The two might then join in the production of the lost parts, so that they would be double in the parts retained, and single in the restored parts. As the specialized parts are the limbs and other accessories, the head, and perhaps some of the internal organs, would be double, while the motor organs would be new and single. They would be the outcome of the tendencies of both organisms and would serve for both, the result being a double monster such as sometimes appears when the two nuclei develop independently. Certainly an analogy for such a combination is found in the established cases of births possessing two heads or bodies and one pair of limbs. If through the inequalities of growth the one nucleus grows more rapidly than the other, the former will enclose the latter and throw its envelope about it so that it cannot break loose and assert itself. When the latter begins to grow, it will distort and transform the outer 
body in which it is enclosed, but it will not be able to escape. All its phenomena will be internal and its influence on the world beyond must be through the agency of the outer body in which it lies buried. There would be two beings partly united, in one of whom growth, and in the other reproduction, is dominant. The former would make up the mass of the body; the latter would be mainly nerves and head. The new parts are due to germs enclosed, and transformed into more or less specialized parts.

The outer body represents a tendency towards mass and bulk; the inner body is a struggle of germs to break forth, and of the effects of the failure to do this. All the phenomena of sex life are repeated again and again, but the ultimate end is not reached because the germs of the other sex can never reach the enclosed ovary. Consciousness, in its primary form, is aroused by the irritation and stimulation accompanying the creation of sex products. Not memory nor will, as we know them, is the first product of consciousness; it is visualization - fancy. The visuali- 


\section{A Possibility}

zation due to irritation in the sexual organs is the readiest and most vivid form that men experience. Other forms could not come into existence if sex visualization had not in its struggles wrought out the means by which they express themselves.

If these statements in any way represent what actually takes place, consequences follow which, in a measure, conform to what we know of organic development. The outer body may be said to be in a struggle with the inner body. It has growth on its side and makes organs in harmony with its needs, while the inner body, inferior in growth, is superior as a means of propagating nervous currents. It, then, is the source of emotions which cut down the outer body and retard its specialization. It endeavors to produce various organs in the embryo, but the inner emotions cause reductions that displace them. The embryo goes through a series of partial developments which are never completed because of the lack of harmony between the outer and inner bodies. So long as new emotions arise from new nervous developments, the organs of the body can never be in equilib- 
rium, and its structure cannot have the stability on which depends the attainment of fixed ends. Growth in the outer body makes folds, and they, as incipient ovaries, give off germs which in confinement become nerves. The new nerves, when organized with those already existing, rouse 'new emotions, and these again reduce the outer body to a mass; and then new growths begin a new cycle that ends in a fresh reduction of the outer body to a lower form of organism.

It would harmonize with my thought if we should consider the sympathetic system of nerves, with its automatic action, as a part of the outer body - a remnant of the many struggles that it has had with the inner body and its central nervous system. It is this vasomotor system that suffers the most in the expression of the emotions, and there occur most of the reductions which they cause. In it we almost have a body without a mind, and in the inner organism we, to a like degree, have a mind without a body. The outer body attains mass, but loses the specialization which creates form, while the inner body re- 


\section{A Possibility}

tains its form but loses the mass, which, if retained, would make for it a fitting body. Two abnormal creatures are thus united in a being with both form and mass. We might regard a head as an ovary with retained sex products, which, in their activity and struggles, create consciousness. It must be thought of as a low form of organism - a colony of germs, each of which has a possibility of growth to give to it body, but not enough to make an effective independent unit.

A complex organism of this kind would have two ovaries - an internal one, either male or female, and an external one of the other sex. The internal ovary, as a brain, can determine the actions and form of the whole organism, but it cannot propagate itself. The external and subordinated ovary of the female would unite its products with similar products from the external and subordinated ovary of the male. That which effects the subsequent generation is the union of the germs of the outer bodies of the two parents - the parts of them that have been reduced to mass and hence have never gone through any, or, at 
least, through only a slight evolution. The real developing body - that through which all the adjustment to the outer world is made leaves no progeny, because its germs are enclosed and isolated.

This reasoning, though different from that of Professor Weismann, comes practically to the same conclusion. All the changes through which organisms go, because of their form and contact with the outer world, have little or no effect on the fertilized germ, because the body of which it is a part has not participated in the development through which the parent organism has gone. This, as I view it, is not because the germ plasm is not capable of change, but because the body from which it arises has not undergone change. So far as it has been affected by the changes through which the organism has gone, they have been disadvantageous and not beneficial. Could the inner germs of the two parents have been united, the result might have been different, for then the effect of individual experience on sex germs might have been tested. The continuity of the germ plasm, although a fact, may 
be so not from any inherent difficulty in making a change in it, but from the difficulty of getting the germ plasm in which the change has been made into a position where it can be fertilized, and thus permit of its continuation. The changed germ has a brilliant record as the source of consciousness, but it must lead the life of a celibate and leave no progeny.

Professor Weismann assumes that there is a doubling division of the cell, in which each resulting mass is precisely like the other, and also differentiating divisions, by which one set of determinants is marshalled in one portion, and the other set in the other portion. Doubling divisions yield germ cells, and differentiating divisions yield somatic cells. Professor Hertwig, in opposition to this, affirms that all divisions are doubling divisions. ${ }^{1}$ I am inclined to take the other alternative and affirm that all divisions, except in the simplest organisms, are differentiating. Growth must be dominant to produce a group of related cells, and while it is dominant, the complexity of relations and the increased strength of the

1 See his "Biological Problem of To-day," p. 77. 


\section{I 4}

Heredity and Social Progress

envelope cause cells to become increasingly complex by preventing that quick, complete division characteristic of unicellular organism. Differentiating division is little more than incomplete division, by which parts readily thrown off under simpler conditions are retained and aggregated in ways least hostile to further union. This tendency results in increased complexity and differentiation so long as growth is dominant. When, however, the process has been carried so far as to make the union unstable, or when the growth forces slacken, the delayed divisions complete themselves, and some, at least, of the cells are brought back to their original simplicity. Germ cells are therefore not simple divisions of the first cell, but are at the end of a curve of development which in its first part becomes increasingly complex, and in the latter part, through devolution, regains the simple state of the first cell. The germ cell, ready for fertilization after the final reduction, is not then a simple division of the ancestral germ, but is the last stage of a devolution that separates it from the parent organism. 


\section{SUMMARY}

I. If folds become ovaries, where sex products generate, each organism has enclosed ovaries that open inward and exposed ovaries that open outward. If both of these break through the envelope, forms of life arise with two sexes, as in the case of some plants. If one remains enclosed, it becomes, in its struggle for freedom, a seat of consciousness with all the phenomena that sex irritation can create. This, in its primary form, is not memory and will, but visualization - a struggle to picture the complementary self with which its isolated position prevents it from blending.

2. A brain is thus an enclosed ovary with its contents of undifferentiated cells put to a new use. The enclosed ovary is of the opposite sex to the exposed ovary, and hence beings manifest mentally the characteristics of the opposite sex from what they are physically.

3. This is one possibility. The same results follow if each of the two nuclei which come together in fertilization keeps its independent life but unites to create the motor organs on which development and adjustment depend. One nucleus becomes enclosed, and in its development creates the spinal cord and brain.

4. A third possibility is that the union of the male and female nuclei forms a neutral base from which there is a complementary differentiation. In the one direction the cells tend to become anabolic and in the other katabolic. The organism is male or female, as the anabolic or katabolic cells dominate in growth and enclose their weaker 


\section{6 Heredity and Social Progress}

rivals. Germ cells and thought cells are at the ends of the series, but which is the one and which the other depends on the accidents of growth. The differentiation of cells and the conversion of one group of sex cells into thought cells would happen in either case.

5. Nerves are not the result of mere growth through which complexity and differentiation increase. Before they appear devolution must create tendencies toward reproduction. The subsequent regeneration of these parts in confinement transforms what would be motor organs into nerves. Losing the power of movement they become the paths over which nervous impulses are transmitted. 


\section{CHAPTER X}

\section{Devolution}

GRowTH is usually contrasted with death, for when the period of growth ends the decay begins that ends in death. Growth should, however, be contrasted with devolution - a tendency of complex organisms to break up into parts. Even if this rupture is accompanied by decay of the organism, regeneration may take place if there is a sound core in either part, and the organism be brought back to its former vigor. At least this is true of many animals, and if the preceding argument is correct, the principle holds for all organisms. Growth is not a steady process. There are periods of increasing specialization, of despecialization, and of simplification, these in turn being followed by regeneration and new growth. The regeneration of parts follows unless the disruption prevents access to nutri- 
ment. Death is not due to katabolic destruction, but to the failure of the anabolic process which naturally follows it. Nature gives to all organisms the means of ejecting waste material. It is not, therefore, destruction but starvation which causes death. The disease which is not starvation is due to the uneliminated refuse that blocks the access of nutrition or forms noxious chemical compounds.

The nutriment that is transformed into cells is not all deposited at one part to feed continuous growth, but at two or more alternating parts. If growth begins at an undifferentiated cell, additions will be made first on one side and then on the other. The formation of new cells continues as long as nutrition permits this alternating activity. To arrest growth on one side is to arrest it on the other, since one side cannot be continuously anabolic. Let us suppose one side to be injured through disruption, and its complexity reduced several degrees: in order for growth to start afresh, the other side must be correspondingly cut; this is accomplished by means of disruptive discharges which wear away the one-sided growth until a 


\section{Devolution}

point of equilibrium with the other side is attained. Then growth begins, and both sides are restored to their former completeness. Growth being bilateral, a set-back on one side must be followed by a set-back on the other before a forward movement can be resumed. It is a balanced process demanding an equilibrium as a basis of its activity.

This fact necessitates devolution in complex life processes. Single cells cannot be added to restore an equilibrium between two sides, although these cells may be destroyed and eliminated. Vital equilibriums are, therefore, obtained by backward movements; balance is restored by a subtraction, not by an addition. If a plank be so balanced that a slight difference in the weight of the two sides will disturb it, a block may be added first to one side and then to the other until a large number is piled on each side. If a dozen blocks were suddenly knocked off one side, the only way to keep the equilibrium would be to knock off a dozen from the other. Then the original number might be restored by adding one at a time. Addition is a slow process; subtraction may be 
a swift one. Rapid shiftings of large amounts are made by subtraction in every process where equilibrium is preserved. Vital processes also depend on this principle. Growth alternates between two parts, while the destruction, which disturbs the equilibrium on which growth depends, is limited to one part. Devolution must, therefore, operate as the subtracting force upon related parts until an equilibrium is formed. Then growth asserts itself and life is revived.

The agent of devolution is emotion. Adverse conditions, the source of emotions, cause a shock or a nervous explosion which follows, not the bilateral paths of structure, but the most direct routes for its dispersion. If this leaves the organism in an unbalanced condition, devolution must create an equality by cutting back the unaffected parts until growth can assume its normal course. Emotions always arise where there is a lack of balance between two related parts, and disruptive activity continues until despecialization and simplification restore the equilibrium. Unbalanced katabolic processes destroy until the restored 


\section{Devolution}

equilibrium permits nutrition again to act. Isolated katabolism brings dissolution; katabolism alternating with anabolism permits growth. Disruptive katabolism, emotion, and devolution are one, and they ensue when there is a disturbed equilibrium within the organism, or adverse elements outside of it. They act upon the organism until the new conditions are met, when a forward movement takes place along new lines.

These facts have a practical significance in the sudden cures arising from emotional causes. Disease causes false growth at particular points, and in order to preserve equilibrium, false growths occur at other points. An explosive emotion disrupts some of them, and then the lack of equilibrium starts other destructive forces which do not cease until the whole organism is placed in a new and simpler balance. Then new growth can take place to restore the former complexity in healthy directions. Destructive losses may weaken, but if unhealthy parts are eliminated, a new vigor may soon be attained, and the organism be restored to its former condition. 
Emotional cures are associated with religion and are looked upon as miracles by those who believe in them, and are doubted by those who reject them; but there is no need of so classing them if the principles of devolution and regeneration are understood. That which is marvellous as an unexplained fact becomes simple if viewed as a natural event. Religious excitement creates nervous shocks which disturb balance, devolution acts to restore the equilibrium, and then regeneration creates a healthy organism. Disease is thus eliminated by cutting off its false growths.

Any strong emotion will do this if its activity affects the diseased parts. Even a change of environment may create the needed emotions and give back health, but here, in distinction from the cures effected by religious emotion, there seems to be a growth and not a set-back that eliminates. In this case, however, we must remember that the emotions of the change precede, and that they incite the devolutional forces of regeneration. A game of cards, a night at the gambling table, or the 
sudden plunge into dissipation of an overworked man may, by creating strong emotions, also effect cures. ${ }^{1}$

A shock acts more quickly than thought, and when the physical change is made, the return of normal conditions does not restore the original state. We often speak of those breaks as a change in the current of thought and imagine this to be an explanation, as though a current of thought had no physical background. Ideas, however, act through structure which must change in order to permit a change in the current of thought. There must be a devolution of structure to

${ }^{1}$ An incident which occurred while I was writing this essay well illustrates emotional effects. I was taking a walk in the depressed mood which is the natural result of melancholy and the discouragement and isolation belonging to it. Happening to look up, I saw above the tree tops in large and vivid letters the word "love." A man must be constituted differently from me not to be strongly moved by the sudden shock of the sight. It seemed an unaccountable event, and yet, the cause was simple enough. I was approaching a hotel on the top of which the landlord had put a sign. The trees had grown from the side I was approaching in such a manner that they hid everything but those four letters of one of the words of the sign. To recognize this took but an instant, but in that instant a change was wrought which cured my melancholy. 


\section{24}

Heredity and Social Progress

break one current, and the growth of another to permit new ideas or to bring them back to normal channels. These physical changes due to emotion are, I take it, the causes of the cures of every deep religious awakening of the past, now so often heard of in connection with Christian Science. Ideas move through structure; morbid structure forces thought into depressing channels, but excise this structure, and a new growth will bring back the elation of health and its faiths and convictions.

It is a mistake to assume that a sudden cure must have some powerful cause. In truth, the slightest causes are likely to produce emotional effects; the only condition for their efficiency is that they shall be unexpected and shall strike bodily structure adversely and without warning. However slight this disturbance may be, the principle of equilibrium will do the rest. Disease is not necessarily decay; it is sometimes a false growth and follows the laws of growth. Devolution must precede any normal growth, and for this end emotion is most effective. 


\section{Devolution}

And why is this devolution easy? In the first place, because organisms are bilateral and growth alternates between the two sides. But more than this, human beings, at least, are a combination of anabolic and katabolic tendencies between which a constant equilibrium must be preserved, as it is in men, whose inner being or mind is anabolic and whose outer body is katabolic, and with women in whom the opposite is true. Each self acts on the other, not directly through muscles or nerves, but through emotions. The outer body must despecialize to match the conditions of the inner body, and the inner body by the same resource must attain an equilibrium with the outer body. The equilibrium comes in all cases indirectly through devolution, and not directly through growth. Any divergent tendencies are cut off by emotional set-backs which cease only when the two parts receive a common impulse to grow in one direction. Devolution is thus easy, effective, and increasingly prominent as organisms rise in the scale of being.

Physiologists seem recently to have proved 
that life is a series of ferments. ${ }^{1}$ Growth is obtained by one series of ferments, and a cutting back or dwarfing results from another. The process of growth is thus reversible. An organism grows under favorable contact and draws back or shrivels under adverse contact. If this is true of the chemical ferments in cells it confirms my contention that adverse contact incites devolutional forces among the cells of an organism, and reduces the parts they affect to a greater simplicity. Every adverse contact with the environment brings a recoil, and the emotion is the psychic expression of its physical effects. Growth begins anew when the adverse contact ceases. Beings do not adjust themselves to an environment and afterward remain stationary until a new adjustment is made possible by changed conditions. They continually press forward toward new adjustments and then are set back by adverse contact. These constant forward and backward movements make regeneration possible and give a plasticity to tissues

${ }^{1}$ See an article on "The Newest Concepts of Life" by Carl Snyder, in Harper's Magazine, November, 1902. 
and organs which causes them to respond more fully to the environing conditions. Life is a rhythm between favorable and unfavorable contact, and each higher form of life is an expression, in some complex way, of the primary rhythm on which all life depends.

\section{SUMMARY}

I. Growth is not a steady process. Periods of increasing specialization are followed by others of despecialization and simplification. Regeneration follows disruption if access to material is not prevented.

2. When growth starts from an undifferentiated cell, new cells are added alternately on each side, so that a balance is maintained. If growth stops on one side, it ceases on the other. When one side is cut back or ruptured, the other must be reduced to a like degree before fresh growth begins.

3. This cutting back is devolution. Equilibriums are obtained by backward movements. Sudden changes are made by subtraction, not by addition.

4. The agent of devolution is emotion. It arises when there is a lack of balance between two related parts and produces shocks until despecialization restores the equilibrium. Tendencies toward an equilibrium are tendencies toward simplification, which remain active until the complexity and differentiation of growth disappear. Then fresh growth restores all, or even more, than was lost.

5. Emotion may thus be the cause of cures. Many dis- 


\section{28}

\section{Heredity and Social Progress}

eases are not a cause of decay, but a false growth which an explosive emotion may disrupt. The organism through devolution is cut back until only a sound core remains, and then new growth in normal directions restores health.

6. Ideas act through structure, and this must be altered to permit a change in the current of thought. A devolution of structure breaks one current, and a new growth arouses another. Regeneration is not a mere mental state; it involves a physical change. 


\section{CHAPTER XI}

\section{Character}

IF the shock of non-adjustment arouses emotions, and these emotions induce a devolution which cuts the organism back to simpler forms, the question arises whether there is not a reverse process by which motives arising in organisms may force changes in the environment. In short, does any shock of non-adjustment arouse impulses which seek an outlet in ways modifying present surroundings or compelling a movement away from them? If there is no such impulse, we must assume that all changes begin in the environment and end in modifications of the adjustment-seeking organisms.

There is at least a strong popular belief in such motives and their effects. We customarily say that men "have character," when, in distinguishing them from the mere passive recipients of environmental pressure, we point 
to their power of resistance against it, and to their developing force acting on other persons, or on external conditions.

To determine the truth of this distinction we must start from the economic conditions upon which life depends. An economic surplus is followed, first, by organic growth and then by emotional changes that disturb present adjustment, and force an entrance into a new environment where the new characters find a field of activity, and bring about a new adjustment. But an economic deficit blocks the first step in this series of changes. It not only prevents the formation of new tissues and organs, but it hardens those already in use and confines the flow of nervous currents to increasingly definite channels; it therefore aids in the formation of acquired characters which help the individual in his own adjustment to present conditions, but are not inherited by his descendants. A deficit does not develop new natural characters; it can become a cause of progress only by conscious means, and through agencies which must be evoked anew in each generation. With it is handed down, 
from father to son, a tradition, a custom, a moral rule, or an imitation, but not an organic modification. It is a psychic, not a biologic, inheritance, and represents the sum of the acquired characters that have proven of use to the species or the race. If acquired characters are not inherited, a local situation cannot mould character; they will be made effective only through tradition, morality, and imitation. Deficits act through these agents, and force upon each age the acquired characters of past ages in a strict routine from which no escape is possible.

A surplus, however, creating organic modifications finds a psychic expression in an impulse. I define an impulse as surplus energy not used in routine acts. This energy effects changes, but has no fixed routes of exit. Let us notice the result of this distinction: deficits build tradition, morality, and imitation, through which activity is forced into fixed channels useful in the present situation; a surplus makes organic changes and evokes impulses which have no fixed channel. This flow of energy, modifying organism and environment, is the 
source of natural characters which destroy present adjustment and so alter the environment that better adjustment is possible.

It is these natural characters which, summed into the name "character," are so highly prized by society. We admire in a man the willingness and ability to confront his environment and to transform it to suit his purposes. Character is the culmination of a series begun by a surplus, just as morality and imitation end the series in which a deficit is the first term.

If surplus energy in the form of impulse were the only effect of an economic surplus, the persons who first enjoyed it would be impelled to increased activity, while in their descendants resultant organic modifications would ultimately develop natural characters. Then "character," as we use that term, appearing in descendants, rather than in those who had created the economic surplus, would be a thing of slow formation and not that rapid transformation we so often see. There is, however, a possible alternative. Every complex being has partially used organs which are capable of being more fully aroused anew. In 
the transit to new environments some parts of use in earlier times or in earlier stages of development become dormant and are not called into activity so long as an economic deficit prevents the generation of surplus energy. Routine activity makes the first claim on energy, and if there is no surplus, absorbs it all. But with better economic conditions comes a flow of surplus energy which will not be exhausted in routine activity, but will seek exit through the unused parts and stimulate them to a renewed activity. Muscles developed for walking may now be used in the dance; vocal organs developed for speech may now be used in song; and finger muscles developed in plain acts of grasping may now be trained to intricate coördination in playing a musical instrument, or applied with increasing complexity in the deft manipulation of the finer manual arts.

The transformation of organs is greater than is implied by these illustrations. If there is an element of truth in what I have said about the existence of an outer and an inner body, each physical organ has a correlative structure in the central nerve ganglia. As the outer body 


\section{I34 Heredity and Social Progress}

goes through the various stages of development from the embryo to maturity, a series of organs appears and then disappears. There is apparently no force cutting back the inner nervous structure. After an embryo has gone through the fish stage, the outer organs of the fish disappear, but the psychic mechanism that moved these organs may remain. Advanced beings may then have fish thoughts - imitation, for example - without any visible fish organs. There are thus many inner processes that have no outer expression, or at least the outer organ is much dwarfed and seldom vitalized with energy. A flow of surplus energy through the brain makes these organs of inner expression active without an effective external expression. The nervous circuit then starts from the brain and brings back an impression apparently from the outside, but which in reality has been caused by the outflow of energy from the brain. Such impressions seem external, although created in the brain. They will modify the person's concept of the environment, and consequently his subsequent activity, as much as if they were really objective. Surplus energy can thus ob- 
jectify concepts and create beliefs by following definite paths - natural routes of exit laid down during an earlier development of the race which have always remained available and are again utilized by surplus energy. Definiteness of action is thereby assured to people with surplus energy which would not be possible without this earlier development and subsequent abandonment of organs. On the other hand, the energy now flows in fixed channels counter to present conditions. We have this phenomenon illustrated by religious conversion, when a person under strong impulse changes his activity from wonted ways to the performance of deeds he had not desired to do in his previous life. He now acts from motives hitherto unknown, and opposes himself to his environment and to the demands of his earlier experience. A gulf divides his life, and he has an impetus toward forms of activity which will become effective only through radical changes in the environment or in social conditions. A surplus is quickly transformed into emotions and impulses which make men discontented with existing conditions, and the 
activity evoked we accept as evidence of character. Deficits arouse one part of a person; surpluses arouse another. The first ends in a tradition, a morality, and other acquired characters; the second is the source of new natural characters not produced by the routine of life.

Character represents the sum of psychic forces adverse to environment; emotion has its origin in the environmental elements adverse to the being which seeks adjustment. Character destroys adjustment by modifying the environment, emotion by modifying men. Neither emotion nor character completes itself in mere adjustment to existent conditions. When aroused by a surplus both impel toward a super-adjustment which demands more elements for a complete harmony than are found in the present wrought-out adjustment. The equilibrium sought by character and by emotion is not in the acquisition of the good, - the summum bonum of experience, - but in something beyond the goal of conscious utilitarianism. There is a super bonum which includes this good and more, and only when surplus energy incites a movement toward this complete 
end, are the natural impulses and emotions fully satisfied.

If deficits end in acquired characters, such as local traditions and a moral code, they will impress motives of economy and of self-assertion. Selfishness is a consciously acquired aptitude due to existence under conditions which have created a deficit. Self-interest acts either through imitation or through a rational utilitarianism. It is not a natural character; it is the acquired result of a deficit. Altruism, however, is an inherited impulse aroused by a surplus which moves outward through characters not created by the present environment and, hence, not determined by it in their activity. So long as the surplus continues, the conscious attitude of the recipient is altruistic and the surplus is used for other than individual ends. A struggle now begins between the motives resulting from a surplus which acts through newly aroused natural characters, and the rational or imitative habits which, as acquired characters, are impressed upon men by their inherited traditions. The intensity of selfishness is determined by the number of 
acquired characters that are effective in adjustment; the intensity of altruistic impulses is likewise determined by the number of natural characters made active by a surplus.

Acquired characters, it must again be said, result from the direct action of the present environment, while natural characters have sprung from conditions of earlier environments no longer operative to force reactions in harmony with them. Inherited reactions are free from environmental control, and act, not only independently of it, but even directly contrary to it. A scientific analysis of character thus justifies the popular view of it, and shows how resistance to the dominance of present conditions is the necessary precursor of any improvement in them.

\section{SUMMARY}

I. All natural characters are due to the indirect action of a social surplus. Deficits are guarded against by acquired characters. The conditions that cause an elimination are due to the presence of a deficit. Therefore a deficit cannot create structure or be the means of evoking natural characters.

2. Character is action which modifies the environment 
instead of affecting adjustment. It represents the psychic forces adverse to the environment, and is equivalent to the natural characters of the biologists. Emotion is the subjective expression of the elements in the environment adverse to the adjusted being. All new forms of natural adjustment are wrought out through these forces.

3. The present environment does not act on men through natural, but only through acquired, characters. There spring up in each environment traditions, customs, and habits which must be retaught to each generation.

4. Emotion and character do not complete themselves in present adjustment. They impel toward a super-adjustment in which future additional elements can be harmonized.

5. Natural characters are made active only by surplus energy. A deficit renders them dormant and causes conduct to be determined by the acquired characters of the present environment. Persons and classes living under a perpetual deficit have no opportunity to reveal their natural character. They must be controlled by tradition and imitation until a surplus destroys the dominance of acquired characters. 


\section{CHAPTER XII}

\section{The Inner Organs of Expression}

ACQUIRED characters have no natural organs of expression. They become effective through emotions that arouse motor mechanisms created for other ends. These acquired characters, failing natural expression, when viewed from a social standpoint, are morality, tradition, habit, and imitation; from a psychological standpoint they are associations or, more technically, associations of ideas. Starting from their economic antecedents, they are due to deficits that save energy by forcing economies. Surpluses forge structures through which the resulting ideas find their own means of exit, and, if they appropriate any of the existing structures as means of exit, they thereby destroy some traditions or imitations in the social world and some associations in the psychic field. 


\section{The Inner Organs of Expression $14 \mathrm{I}$}

Such social and psychic results of deficits massed together are the social heritage. The particular forms in which they appear in one generation would not reappear in the next if there were not some contact between the two generations and some discipline by which the ideas of fathers are impressed on sons. Few persons who follow biologic discussion will deny that traditions, morality, and other recognized social phenomena are acquired characters which lack natural means of expression. It does, however, seem that mental associations are natural characters.

To determine this point we must return to the elementary facts. Growth, I have often affirmed, is double. There is an inner neural body that parallels the outer body in its development, and between the two there is an interchange of effects, so that the devolutions and evolutions in the one effect similar changes in the other. There is a difference, however. The inner body, from its protected position, is less affected by evolutional and devolutional forces than is the outer body. A useless outer organ would be a serious detri- 
ment in survival and adjustment. Radical alterations in the environment must therefore make marked changes in those outer organs which affect immediate adjustment. If an organism changes from a life in the water to one on the land, devolution must cut off or powerfully alter the older organs and new organs must develop to supplement them where they are incapable of modification to meet the new conditions. By the force of these conditions the older organs in the outer bodies of men have practically disappeared. Men do not have the gills of fish or the tails of reptiles.

If there is an inner body of parallel growth on which emotion and devolution have less effect, these primitive organs would remain and be capable of activity in men. We would, in other words, have fish thoughts, reptile thoughts, and monkey thoughts, even though the outer organs through which these inner organs once found expression no longer exist. Is there any way of testing this supposition or of observing the activity of inner organs which have no outer organs of expres- 
sion except through the motor organs of use in our present environment? There is; but in order to observe it, a distinction must be drawn between the inner and the outer organs of expression. The action of the outer organs of expression may be readily observed, for every movement visible to the eye is a result of their activity. We may likewise observe the effects of the inner organs of expression by examining the contents of consciousness. Associations of ideas are not mere passive relations, but are the results of the motor mechanism of the mind. Exactly as groups of motor centres act together when you instinctively grasp an object, so do certain inner motor centres work together when you construct a thought from which other thoughts develop either as component parts of the primary concept or as its successors. The field of association, then, is the field of inner activity, and it enables us to measure the extent and the complexity of the motor mechanisms which are active in the mind.

By comparing the field of associations with the field of external activity it can readily 
be seen that associations cover a much larger field than the field of bodily activity. Our ability and capacity to think is far greater than our ability and capacity to act. The inner mechanism is, therefore, much more varied and complex than the outer, a condition which may be explained by assuming that the earlier organs of expression in antecedent life have been less completely displaced by evolution than have the outer organs of expression.

Our assumption, if true, is of importance in connection with a vital biologic problem. Acquired characters cannot be inherited, but they can appropriate the disused inner motor organs not yet displaced by the stress of evolution. Primitive organs are so closely linked by associations to present activities which yield acquired characters that they are able to find a new method of external expression through the newly acquired activities with which they are united. Associations thus give to acquired activities a motor basis that they cannot create for themselves.

One of the most obvious of these agents of 
acquired characters is imitation. We say imitation is instinctive - rightly enough, if we mean mental reactions. But are there any bodily imitations - acts that the body performs by mere contact without any association of ideas? A generation ago the scratching of newly born chickens and a host of similar acts would have been accounted for in this way, but in most, if not all cases, a better explanation is now given. Our outer bodies have passed the stage in their development in which imitation is an available means of adjustment; but the mechanism of imitation is inherited by the inner body and is made active through mental association which affords acquired characters, a method of propagation that otherwise would be lacking.

A second agent of acquired characters is fear. The world was for ages filled with huge monsters which spread death and desolation. In weaker organisms fear made escape the best method of survival. Man belonged in this class, and for ages fear must have dominated him until it became an ingrained feeling which affected every tissue. But in the end man 
became the dominant animal, and the outer organs were remoulded to meet the new situation. A new type of reactions was thus developed, displacing fear. Contact with fire, for example, causes no fear in the outer body. The instinctive act is one of instant withdrawal. The burn acts on the hand in one way; the fear of a burn acts on the mind in another. We have no fears except those due to mental associations. The thought of danger, due to an older reaction, brings mental fear, while the presence of real danger acting on the body gives courage. The inner and outer expressions are out of harmony because the outer expression reflects present reality, while the inner expression reflects only the past of the organism. The acquired characters are made effective through fear, which, in spite of our present environment, retains a place in our thoughts.

The third agent of acquired characters is reason. We say, "It is either $A, B$, or $C$. It is not $A$; it is not $B$; it is therefore $C$," rejecting a larger or smaller series of dissimilars before a similar is accepted. Or, in other words, after a long series of dissimilars we predicate 
the appearance of a similar. Are there any primitive animal functions that act in this way? If there are, reasoning may be the development of one of them.

Recoil from the dissimilar and the acceptance of the similar is an elementary tendency starting with life. The tiny amœba will approach foreign substance and recoil from it if it is dissimilar; it will repeat this act until it is brought into contact with a similar substance, and then it will absorb it. Recoil from dissimilars and the approach of similars are elementary animal functions. Fear is the psychic expression of this bodily recoil; curiosity is the psychic expression of approach. Concepts coming through the senses act on the mind through these agents as physical contact acts on the bodies of simple organisms. What more in essence is reasoning than this? I perceive no new element. Rather does reason seem to be the primary rhythm of the body which, having lost its external expression in many complex regenerations of the outer body, has become clarified in its internal expression, and expresses itself psychically as reason. 
We have retained the simplicity of the unicellular organism in no place so plainly as in our reasoning: here consciousness shows its elementary and primitive character. No outer organ has its simplicity; digestion, for example, now demands a hundred independent reactions.

These three agents of acquired characters - imitation, fear, and reason - are supplemented by one of a different origin. I have said that the outer organs of expression are more subject to change than are the inner organs. The inner organs may therefore force modifications upon the outer organs which adapt them to conditions imposed by the rigidity of the inner organs as well as to the conditions set by the environment. The more rigid alters the less rigid; the environment and the inner organs of expression being more rigid than the outer organs, the latter are cut back by the internally and externally excited emotions, after which they grow again to meet the new conditions.

But this relative rigidity of the inner and outer organs may be changed by bodily disci- 
pline. Repeated acts increase the definiteness of bodily reactions, and if the repetition is frequent and prolonged, the flow of emotion is from the rigidly disciplined outer organs inward to the now relatively less rigid inner organs of expression. The inner primitive organs become more plastic, evolve until they harmonize with the outer organs, and are at length regenerated to conform to present conditions. Therefore, while acquired characters cannot create new organs of expression, they can, through the discipline they impose, regenerate old organs, forcing them to express internally new objective conditions utilized by the acquired characters. Regeneration and conversion are not arbitrary phenomena, but the direct result of an imposed discipline. New forms of bodily discipline thus antedate each new emotion and each conversion.

Let me put this thought in another light. Bodily emotion is the result of the surplus energy created by disciplined motor organs, and it affects and regenerates those inner organs of expression to which we give the name of mental activity. While these inner organs are 
natural one part of them is also primitive. I shall call those organs natural, which have corresponding organs of outer expression, and those primitive which, having no external organs of expression, necessarily use organs over which they must acquire control through mental associations before they can express themselves. When discipline, through a surplus, creates a bodily emotion, it makes the natural organs of inner expression more plastic and breaks up the associations that permit the primitive organs to dominate their activity. Strong emotions will do even more: they regenerate the primitive organs, and force them to receive concepts which shall be useful in the present environment rather than concepts which were natural in the earlier conditions upon which these organs developed. The concepts evoked by this regeneration we call ideals, and deem their acquisition of prime importance in the uplifting of individuals or of society.

My contention is that ideals are not acquired directly through the senses, but are the indirect effects of that bodily discipline which creates surplus energy. An ethical impulse does not 
start in the environment, affecting first the brain and then the body; it begins in improved bodily mechanisms, stimulates mental activity, and finally passes out over the motor organs to act on the environment.

Emotion has two sources and the impulses involved have two routes of movement. The impulse may originate in the environment, enter the brain over sensory routes, form associations, and arouse an emotion which will gain control of the motor organs; or the impulse may begin in these bodily organs as a result of an improved discipline and reverse the route travelled by the other class of impulses. The principle we have again and again emphasized is that emotions cut back the organs, parts, or objects on which they focus. We have, on the one hand, centrally excited emotions which, by weakening mental associations, degenerate the body; on the other hand, emotions and inward-going impulses which regenerate and uplift. The sensory organs permit external impressions to gain direct admission to thought centres; their emotional effects are outward-going and decadent. The develop- 
ment of the motor organs is such that motor reactions arise in every situation, and each failure in adjustment is met by some motor reaction that protects the body. Only surpluses can pass this series of defences and become mental phenomena. But centrally excited emotions pass out over the motor organs along routes where no defences have been developed; they are therefore decadent. Bodily emotions, however, arising, as they do, from an improved discipline, are upbuilding forces.

The distinction becomes more evident by contrasting the environment of the sensory with that of the motor organs. When defects in adjustment affect a motor organ, it develops instinctive adjustments by which injury is prevented. A man going over a rough road calls into action a hundred instinctive movements which remedy the defects of the road. The motor environment is provided for by organic adjustments. But no natural safeguards exist to remedy the defects of the sensory environment. The shocks of nonadjustment go direct to the mind, disturb its 
delicate adjustments, arouse a sense of fear, and then depress or disarrange the motor organs by striking them in the rear. The only defence against the evils of centrally excited impressions lies in discipline. Where there is no natural defence one must be built up. The discipline of the inner organs of expression is mental association; that of the outer organs is in the motor response of manual training.

Centrally excited emotions are an evil unless held in check by one of these means. The sensory environment extends so far beyond the real environment that no natural adjustment is possible to much of this realm. A vague pseudo-environment exists of which the mental effect is fear and the bodily effect is nervousness. The only emotion worth anything is the emotion due to the surplus energy generated by some bodily mechanism. Centrally excited emotions often come from a pseudo-environment that is not vital, and in their activity they break the discipline on which all upbuilding processes depend. 


\section{SUMMARY}

1. Since growth in higher organisms is double, there are two groups of organs through which energy is expressed. The expression of the outer organs is through bodily movements; that of the inner neural organs reveals itself through mental associations. These inner organs of expression are the vehicle of acquired characters. They are cut back by devolution less fully than the outer organs, and hence many inner organs of expression which have no parallel outer organs persist from earlier stages of development. These primitive organs are linked to the acquired characters which through them obtain organs of expression.

2. All acquired characters act on the mind through the association of ideas; they never evoke new agencies through which to act. The agents of the acquired characters are imitation, fear, and reasoning. Each of these is the development of primitive characters which now have no outer organs of expression.

3. Another agent of the acquired characters is discipline. It acts primarily on the outer organs of expression and makes them so rigid that emotions pass inward and regenerate the primitive organs utilized by the acquired characters. The ingoing bodily emotions are so safeguarded by instinct that they cannot injure the bodily or mental mechanisms. Against centrally excited sensory emotions, however, there are no safeguards. Their physical expression is nervousness; their psychical expression is melancholy; their social expression is decadence; and their expression in trade and industry is a commercial panic. 


\section{The Inner Organs of Expression 155}

4. Selfishness is self as an object of fear. Ethical impulse, however, is not sensory. It is an expression of the surplus created by bodily discipline. Starting from bodily mechanisms, it moves inward with a regenerating force and then outward over improved motor organs. 


\section{CHAPTER XIII}

\section{Some Terms}

Psychological terms, derived from common usage, have become more numerous than the real distinctions they have to make, and are used so loosely that they overlap each other. A fitting vocabulary cannot be formed by mere inductive studies. There is no certainty that the distinctions are real unless they correspond to the physiological facts that create or are synchronous with the psychic manifestations. Every mental fact has some physical expression. The test, therefore, of the reality of a psychic distinction is its correspondence to a physical difference, and this test should be applied in defining terms.

Will and attention are often confused, as when we say we will to give attention. Willing is, however, rising katabolism-innervation of the part aroused and a stronger flow of 
energy. The resultant act becomes more pronounced with the intensification and persistence of the katabolic destruction. In other words, we will better, and with increased power, if we act with speed and with a quick response in energy. A strong will, therefore, indicates that katabolic centres are dominant; a weaker will implies that anabolic centres, with their slower and less effective responses, are in ascendance. These responses are attention - a quality of anabolism, because in anabolic cells, at every step, changes take place more slowly, and also continue longer, than they do in katabolic cells. Such cells, then, afford more time for attention, and prolonged attention checks bodily changes. ${ }^{1}$ Willing and attention are opposites. Men with strong wills are poor at analytic thought, and careful thinkers hesitate when in action. As we gain in will, we lose in thought power, and we gain in thought as we lose in will power.

An application of this truth brings us back to the assumption that each being is a combination of two selves, one anabolic and the ${ }^{1}$ Ribot, "The Psychology of Attention," p. 20. 
other katabolic. In woman the outer body is anabolic, the inner is katabolic; in men the opposite is true. The well-known mental peculiarities of the sexes correspond to this difference: men are good thinkers, that is, innerly anabolic; while women are quick in decision; that is, innerly katabolic. If the metabolic changes back of thought come quick and strong, decision is prompt and accurate. If they are slow, attention and analysis are good, but action is less effective.

The word "emotion," so often used in an indefinite way, is used by me as the index of bodily changes. When defined in this way pleasure is not an emotion but an alternating discharge of surplus energy and is therefore to be associated with growth. We find pleasure in the causes that create growth, and emotion in the adverse elements which, reducing the organism, permit regeneration.

Viewed organically there are three fundamental processes - growth, devolution, and regeneration. Organisms grow under favorable conditions. They devolve towards their undifferentiated beginnings under adverse condi- 
tions, and then they regenerate when these adverse conditions have been overcome or avoided. The psychic expression of growth is pleasure; that of devolution is emotion, and that of regeneration is will. Will is an expression of the reaction against adverse conditions and is an indication of the passing over from a state of devolution to one of renewed growth. Will is non-mechanical because the preceding devolution has destroyed the structure through which energy would act. In regeneration new structure is created. The non-mechanical feeling before the structure is created is will; the mechanical feeling after the structure is created is pleasure. Will precedes structural growth; pleasure follows it.

There is a third feeling with a bodily cause which falls under neither of these heads. I shall call it elation, although in its intense forms it is better known as ecstasy. It is the feeling of a dormant part made active by unusual conditions. Elation arouses the whole organism and makes it respond readily to mental stimuli. Under ordinary conditions only a part of each organism is really alive in 
the sense of creating the changes on which life depends. Men are usually much below the limit of their possibilities, and in reaching this limit they stir up powers and make parts active that on ordinary occasions do not act, or at least act rather ineffectively. Elation is the pleasure of these revived activities. It is always combined with increased power of visualization in which a complement is pictured; the idea of the absent member arouses the stimuli and causes the bodily effects which the presence of the absent member would have aroused. Associated ideas stand in the place of concrete stimuli and affect what they would have affected.

Let us put this concept into a concrete form by thinking of the outer and inner body in harmonious relations, so that there is a part in the one correlated to every part in the other. Now cut away the related part in one body, and the corresponding part in the other body becomes dormant. Visualization excites the thought which this absent part would have naturally created, and this thought is the stimulus that arouses the corresponding part 
in the outer body. The thought and the feeling in the dormant part give us an ideal and the resulting elation.

We place certain relations complementary to men in our thought of God, whereupon parts in men that have no present organic use or are but slightly used are stimulated to activity. A religious enthusiast is organically more active than one who responds only to the organic stimuli needed for present life. The elated lover also has enlarged physical and mental activities, and the products of the latter he attributes to the object of his love. An ideal becomes a motive, and demands a greater and more persistent activity than normal bodily needs create. In the allurements of vice the same process operates. When some dormant part of the organism is made active, weak men impute to the material source the pleasure that the renewed activity creates. Normal persons abhor vice because all their faculties are excited in normal ways, and they see in vice only its misery. But make men abnormal and thus render dormant some of their parts, and a picturing begins which attributes to the 
vicious act all those ideal relations that are necessary to revitalize the dormant part. Then a vice becomes to its devotees what God is to the enthusiast, or the object of love to the lover, and includes all the complementary relations necessary to arouse the full organism. It is therefore a religion, but a bad one. It is a love, but degrading. Its origin, none the less, is similar to that of other ideals, and its effectiveness as elation must be admitted. It can be eliminated only by making men normal and by giving them some outlet for every impulse.

\section{SUMMARY}

I. Psychological distinctions should conform to the physical background to which they correspond.

2. Will is a manifestation of katabolic activity and is more pronounced in centres where the response to stimuli is quick and certain. A strong will means therefore the dominance of katabolic centres.

3. Attention is not will. It is best where changes come slowly and abide the longest time. It is greatest in anabolic cells, and the power to think clearly grows as thought cells become anabolic. Decision is katabolic; thought is anabolic. They are therefore apposites, and the one grows as the other falls off.

4. Pleasure is not an emotion, but is the index of growth 


\section{Some Terms}

and appears where surplus energy makes alternating discharges of energy possible. In contrast with it is the elation or ecstasy due to the arousing of dormant parts. The routine of life calls into play but a part of each organism and often hardens its overused parts into feelingless structure. Unusual stimulation is needed to invoke the maximum activity, and when it comes the flow of feeling is distinct from normal states. 


\section{CHAPTER XIV}

\section{Education}

IN the popular view, education is a problem of addition. The mind is thought of as a storehouse where incoming goods are packed better by the wise than by the ignorant. Or, in another way, the same thought is emphasized when the brain is referred to as increasing in size or weight. If the mind is a storehouse, the more compartments it has the more material can be put away to be brought out when needed; indeed, the physiology of large brains seems to support the analogy and to justify the belief of men that knowledge is merely a matter of addition. This also is the thought back of the theory of the mind associated with cell growth and which appears to me to be little more than a clear statement of the popular theory. The public finds, in new language, the ideas it has held for ages, and 
accepts them, not because of the biologic proofs, but because they coincide with the accepted view. What are "ids" and "determinants" but new names for the old apartments in which the mind is assumed to be divided? And the more one has of them, the greater is his power to struggle and to survive. We must therefore increase the number of apartments, the weight or the size of the brain, or the number of ids and determinants. All this is the same thought expressed in different words, in whatever form it reflects the popular thought. It may be called progress by addition, for it assumes that additional matter makes for superiority and determines contests in survival.

I do not intend to argue against this theory, or to establish another one. We need not so much proof of a new theory as a clear presentation of the basis on which one may rest. Men adopt a theory to explain facts, but the old one survives, in spite of inherent difficulties, until the new is so clearly formulated as to displace it. I wish, therefore, to contrast a theory of progress by differentiation with a theory of progress by addition, and to show 
how the acceptance of the former would modify men's ideas of education.

A theory of differentiation implies that two differentiating objects are so united that the strength of the whole is not that of each part in isolation, but that of the strongest of both parts in union. There is then a division of labor by which each part does what it is best fitted to do and the combination makes for strength. Each person is made of combinations of anabolic and katabolic cells. If the outer body is anabolic, the inner body is katabolic or the reverse. In the former case we have a woman; in the latter, a man. But even if the detailed proof I have given is not accepted, there is much inductive evidence that the internal phenomena of men and of women are the reverse of their external manifestations, to support the general facts against any weakness of the detailed proof. Whatever advantages accrue to anabolic tendencies reach the race through the bodies of women and the minds of men, while katabolic dominance expresses itself in the minds of women and the bodies of men. Women think quickly, 
and to them come the advantages of decision; men think slowly, and theirs are the gains of clear analysis.

If these facts are accepted, we progress through an increase of differentiation which intensifies analytic and katabolic tendencies. ${ }^{1}$ The strongest example of one extreme would not be so potent as any combination of the two. Elimination injures because it throws back differentiations towards their undifferentiated beginning. There is a net loss if in struggle either the anabolic or katabolic is cut off. We need both the more anabolic

1 I do not mean that all differentiations are based on these tendencies. They are also complex in nature and have many physical and chemical elements that vary according to their own laws. They are merely representative differentiations brought into prominence by the recognized differences between male and female. The real point is that developed organisms are made up of delicate equilibriums, the changes on one side being in an opposite direction to those on the other. If one gland is acid some other is alkaline, and if one is disturbed so as to make it more neutral, the other is also brought back to a less differentiated state. The higher the organism the greater the number of these complementary differentiations and the more delicate is the equilibrium that must be maintained. We should think of ourselves as a loosely organized group of units, each of which is balanced with some other and subject to destructive emotions if this balance is disturbed. 
and the more katabolic and we need them combined in different ways in men and women. We cannot eliminate women and have men because men happen to be a bit stronger, nor can we eliminate the anabolic or katabolic because the other has more individual strength. Anabolism in men gives clear logical thought; in women it makes good mothers. Katabolism in men makes them strong, active, and productive; in women, it gives instructive, sympathetic, and emotional action. If struggle eliminates sympathy and emotion from women, it eliminates at the same time the strength and energy of men, because both these sets of qualities represent the tendencies in beings toward katabolism. Good mothers and clear thinking in men also belong together and represent the anabolic tendency. It is a commonplace that great men have good mothers, but the reason for it is more physical than at first appears. It is not that as a good mother she influences the character of her son, but that men are internally what women are externally, so that physical heredity of the 
mother becomes the mental heredity of the son. Make good mothers and they will bear great sons because the mind of the son is the doubling of the body of the mother.

I may be wrong in detail, but if this principle is in a measure correct, education is a double process. In certain relations anabolic qualities are strong or weak; while where they are strong or weak, katabolic qualities are of the opposite degree. Where men are physically strong or mentally weak, there women have naturally the opposite quality. Together they properly supplement each other and as the differentiation becomes more pronounced, the mutual dependence of the sexes is increased.

We are therefore approaching, if we have not already arrived at, the time when more use must be made of these facts. Isolated men or isolated women are not able to make any real social progress. As men develop, we gain at certain points, but we likewise lose at others. Civilized men are clear in thought but they are indecisive in action. There is an increasing loss each year because educated men have so little decision that the control of affairs goes to 
less developed types. The education of men and the growth of their vices are simultaneous because vice is indecision and a result of the same causes that clarify thought. So long, then, as we attempt progress through the action of elimination upon men, we lose as much as we gain, for if we eliminate the anabolic we gain decision and morality, but we lose clear thought. If, on the contrary, the katabolic is eliminated, thought becomes strong and clear, but the evidences of indecision and resulting vice spring up on all sides. We see that elimination is no aid to progress, and that while it continues there is a mere shifting of qualities with no gain.

This difference leads, though not by the usual method, to a well-known biological distinction. It has been shown that some qualities are natural and come by inheritance, while others have to be acquired by the men of each age. According to the theory I am advocating, this difference in characters is retained, but put into a new form. A natural character is the strong side of each mental unit. An acquired character is the attempt to implant in a being 
the qualities that are naturally lacking. The weak side may be strengthened, but the basis on which it rests will not be improved - it will probably be weakened - by heredity. The result is that if the quality is to exist at all in the descendant, he must acquire it not only as his father did, but perhaps with even greater effort. If, on the contrary, a quality arises from a stronger part of a being, it appears with increased vigor in the descendant and does not require the nurturing necessary to qualities having a weak basis in heredity. Some mental qualities have an anabolic and others a katabolic basis. The first will be natural to men and must be acquired by women, while the second will be natural to women and must be acquired by men. Successful persons must have both groups of qualities.

Men and women tend to be different. They must be kept on an equality by an education which shall give to each sex the characters that are natural to the other. To put it simply, civilized men are good thinkers, the women of their race have strong wills, and education must give decision to men and clear thought to 
women. But these qualities will not become natural in spite of the endeavor to instil them. The differentiation in men and women will gradually increase and the basis on which the acquired characters rest will be weaker. On the other hand, less education will be needed by natural characters. They will simply demand an awakening which comes in due time if the conditions of life are kept normal.

The acceptance of this doctrine would reverse many educational maxims. Holding the mind to be a group of apartments, we try to add more of them where men and women are already strong, and strive to educate women to be good mothers and men to be clear thinkers. But women are made mothers by a natural process. Men cannot improve on it if they would. In spite of all the talk, there is no danger of a race of unnatural mothers. On the contrary, mothers are improving, but by a method that education cannot affect. So, too, men are, to an increasing degree, accurate thinkers. But they would progress without education. Education may rouse their minds at an earlier age, or give to certain individuals 
an advantage over others, but it adds nothing to the clear thinking of the race. Thought is what it is because of qualities men inherit, and will improve only as heredity is modified.

Education has, therefore, little place among natural characters. It has, however, an increasing place among those that are acquired, since the wills of men and the thought of women increasingly need education. The higher level of equality can thus be reached by both sexes: every one needs all the qualities of the race, and his education ought to supplement the natural qualities that heredity has given.

Education is the strengthening of weak characters - those that heredity tends to dwarf by the very differentiation which acting upon other characters renders them strong, natural and more advantageously inherited. Conscious processes must be directed toward the weak side of human nature, to round the character so that in each individual all parts are strong. Education cannot improve on natural characters. Progress is the development of the strong, not where they are strong, but where they are weak. The strength of the 


\section{I74 Heredity and Social Progress}

strong character is the result of a natural differentiation with which men have little to do, but the strength of weak characters is in their hands. Men can level up their weaknesses until their whole nature is strong.

Conscious education now acquires a definite scope in the field where man's power is greatest. The awakening of strong characters requires no stimulus from without - rather should it be delayed than hastened. Real education is the bringing of the weak in one set of individuals up to the level of the strong in others. The standard is always an objective one-the manifestation of the natural characters in the strong. Men's defects may be measured and improved by the standards set by women in whom these characters are natural, and women's defects may be eradicated by imposing on them the standards and the thoughts of men. In so far as education moulds men and women, it will be more effective if the education of men is in the hands of women and that of women in the hands of men. So will education create that equality which the process of natural differentiation prevents. 
The paradox of the situation is this: try to make men and women alike, and they will become increasingly different; try to make them different, and their likenesses will increase. But this contradiction disappears when we see that if the weak sides of men and women are developed, social conditions are improved; where the natural process can work more effectively the natural differentiation of men and women increases. But if all the effort of education centres on the attempted development of strong natural qualities, the effort is wasted, and wrong social ideas are inculcated which reduce the productive power of society. Natural differentiations are checked and both men and women sink back toward that undifferentiated state out of which the race has come.

Besides education there is a discipline necessary to effective activity. Character largely depends on the regularity of action and on the quickness of response. Discipline is a greater directness of action; it is the more economic accomplishment, through the katabolic quick-acting centres, of that which is 
natural to anabolic centres. Discipline is artificial action because of this transference of the motives of action from one class of centres to another. A man is disciplined by the development of his body where the katabolic tendencies are dominant. A woman, however, is disciplined by the development of her mind, thereby displacing the emotional and erratic motives which move uncultivated women. Discipline differs from education in that the discipline of men comes best from men and that of women from women. These processes unite in bringing the race up to its maximum powers: the awakening of strong natural characters comes under normal conditions by a natural process; education strengthens weak characters and brings all to an equality in the standard which is natural in the strong, and it should be conducted by the strong for the benefit of the weak; supplementing these two processes should come a discipline which transfers all action to the more katabolic side of each person. Effective action must be quick and decisive, and this it cannot be except when the centres most easily disturbed are 
taught to respond to the stimuli consequent to every act. Discipline is of the strong and is best inculcated by those most like the one who acquires it.

In this delineation of the natural powers of men and women I have reversed the position ordinarily given to them. Men are usually thought to have character and decision, while indecision and a lack of purpose are the usual charges against women. The popular view, however, emphasizes the primitive. characteristics of the two sexes and not those manifested in advanced races. The primitive man is decisive, but it is an alertness due to wrath. Take away this one motive and he is the embodiment of indecision. So, too, primitive women hesitate, but it is a hesitation due to fear. This one motive typifies the character of primitive women as wrath does that of men. A strong, vivid bodily state makes men act and women hesitate. Exclude these bodily states and the popular notion of men and women fails. Wrath and fear are bodily states, not mental characters; they are diffused conditions, not specially located powers. 
Wrath, therefore, affects the outer bodies of men where they are katabolic, and fear affects the outer bodies of women where they are anabolic. Wrath is natural to men and fear is natural to women, so long as their bodily states control them. When, however, the mind becomes dominant by the displacement of primitive conditions, these traits disappear and the real mental characters of men and women show themselves. Bodily fear in women is replaced by the mental decisiveness of civilized women, and the wrathful energy of men is lost as soon as analytic thought makes action slow and causes men to change from direct to indirect methods. The civilized man loses the effective promptness of primitive men and regains it only by a bodily education that gives him an acquired ability to do that which is natural to women.

\section{SUMMARY}

I. The popular view of education is a theory of progress by addition. It is assumed that the mind gains in strength as new units are added. In contrast with this is a theory of progress by differentiation. Complementary units become strong, each in its way, and supplement each other so that 
the aggregate has the strength of each part at its strongest point. A group of cells, some losing where others gain, may, without any net addition, gradually acquire fresh power and prevent earlier weaknesses. Each centre acts where it is strong, and is protected where it is weak.

2. The difference between anabolic and katabolic cells furnishes the basis for such a differentiation. If in human beings one class of cells dominates internally and the other externally, types of thought and activity can develop that supplement each other. The thought and activity of men and women will also differ and thus furnish additional basis for differentiation.

3. This complementary differentiation does not permit elimination, for both the parts are retained. Any elimination cuts off differentiation and forces organisms back to the undifferentiated equality of cells from which progress took its start.

4. Clear thought is anabolic; decision is katabolic. In each person one of these is natural and may be awakened; the other must be acquired. One type or sex should be educated along lines on which a mere awakening would suffice for the other, which in turn needs education where the natural powers of the first give it an advantage.

5. Natural characters increase in strength through physical differentiations and not through education. They need less to evoke them with each step in social progress. Acquired characters represent the side of each person that becomes weaker by differentiation. They must be brought out anew in each generation, and with each step in progress they demand more attention.

6. Differentiation disturbs the natural equality, weakening one side as much as it strengthens the other. The 
equality is restored through an education in the acquired characters that raises the level of the whole being to that of the strongest racial traits. Without education there can be no equality among advanced peoples. Differentiation is natural; the levelling must be conscious and is therefore expensive. 


\section{CHAPTER XV}

REFORM

Progress depends on two essential qualities, - quickness of action and slowness of thought. The first results from a mental differentiation which increases alertness, and the second springs from an opposing tendency toward slowness. To differentiate and to become strong in one direction, is to remain naturally weak in the other. Education should consciously meet this deficiency. The strong side of each person is the result of a natural differentiation which comes of itself when social conditions permit, but the weak side having no natural support so tends to be dwarfed by progress that care is necessary to maintain its position.

The strong and the weak in men arise together, and are parts of the same differentiation. If a person has periods of elation, due to a fund of surplus energy outing itself through natural characters, he will also be subject to spells of melancholy when his energy is below 
its normal level. The undifferentiated person escapes both of these, or at least he never experiences them in their extreme forms. The highly differentiated person rises higher than the mediocre man when in exultant moods, but he also sinks deeper in periods of depression. His weakness is measured by his helplessness in depression. He thus demands more safeguards for survival.

The empirical and the rational in men also rest on a complementary differentiation by which progress in one direction is supplemented by a like progress in the other. Practical men, disliking theorists, wish all men were like themselves, and yet the absence of theorists would not make practical men more practical. If theorists failed to survive, the seemingly practical survivors would be less differentiated, and hence more stupid. Elimination of either class forces all men back to an undifferentiated mediocrity. For example, it seemed possible in Spain to make people religious by cutting off heretics and agnostics. The result, however, was not the development of religion, but the sinking back of the whole 
nation into the earlier and grosser forms of superstition. Spaniards became alike by descending in the scale of civilization.

Progress then is not the making of the strong, but that protection of the weak by which differentiation becomes possible. A forward movement can care for itself if the initial conditions are favorable, and human efforts are of little avail in augmenting or in changing the direction of these forces. With the aid of their strong characters men may move forward as far as the initial economic forces take them. But these forces will not aid men on their weak sides, because natural changes make individual weaknesses feebler instead of stronger. The series of steps making for progress, although almost complete, lacks enough elements to block progress, when no efforts are made to strengthen the dwarfed characters in men. And strengthening the weak is not a final process, but one which must be repeated by each generation with ever increasing care. The strength of the strong is natural, that of the weak is acquired. The differentiation of powers is the outcome 


\section{4}

Heredity and Social Progress

of natural processes; the movement towards equality must be nurtured. The exploitation of the weak by the strong and the dwarfing of feeble characters by the strong are the natural results of the pressure exerted by the strong. A check to progress here arises for which there is no natural remedy. When, therefore, nations wish to progress, it is these tendencies which nullify their efforts.

A backward race or class need not be radically altered to fit it for civilization. Most of the changes come of themselves if the initial evils are removed. Give the class or the dwarfed character a surplus, and spontaneous changes will reorganize society. The initial step in progress is protection, and a flow of income from the strong to the weak.

An illustration is furnished by the changes in the immigrants to America. A few generations make them completely American, not because the conscious educational process has had sufficient power to do it, but because a few initial changes start a chain of natural causes which strengthen the strong individuals of the new classes and force their trans- 
formation into Americans. Two things are necessary for this: the presence of a growthcreating surplus and the existence of common emotions, so that men's qualities may be uniformly pruned, and may also grow anew in the same directions. The emotions of a race are not a natural inheritance due to growth, but are a part of the social environment of its members, and act alike on all individuals under the stress of the emotions. Regeneration results wherever the surplus permits growth and places the person in proper contact with his environment. Society, therefore, may expect these emotional changes to act upon every class which has gained the surplus on which growth and regeneration depend. It must guard, not these natural results of every forward movement, but the acquired characters which become weaker with progress, and require an increasing surplus in order to preserve the natural equality of classes and of related parts.

The development of a lower race - let us say the negroes in America - does not necessitate remaking the negro by an artificial process. 


\section{86}

Heredity and Social Progress

Set free the series of natural changes, and the final results will take care of themselves. A surplus includes regeneration and new emotions, forces which will act and react until the whole class has been brought up to the level of its environment. Two races in one environment cannot be kept apart except by some exploitation that harms the weaker one of them. The amplest protection and a surplusyielding discipline will stimulate the forces in a lower class which will ultimately raise them to the level of the highest. Each new discipline yields a new surplus which offers emotion and regeneration a fresh opportunity to evoke natural qualities. The more freely we give to the weak, the more is gained by the strong. The morality of similar men is embodied in the Golden Rule, but for dissimilar men the law of service is yet higher. Do unto those unlike yourself what they cannot do for themselves. Let your surplus energy go out through your natural character for the benefit of those who have it not.

Progress cannot end while the natural growth in differentiated strength is followed by a con- 
scious growth toward social equality. The qualities that by natural progress have come to men must be given by them to women, and those that nature has given to women must be instilled into men. And every class must give its strength and characters to other classes and each race its neighbors. Then a new surplus will appear and a new group of natural qualities will be developed in each sex, race, and class. The weakening of the basis of acquired characters will create a constantly enlarging deficit; but, on the other hand, the increasing strength of the natural characters can bear this burden with greater ease.

If progress is by differentiation, the scheme of reform is not the one we should use if progress were by addition. In addition the new quality in the strong needs nurturing, and the weak must be eliminated, for their absence is no loss, but rather a gain to society. But if progress is by differentiation, the weak and the strong arise together, and both are indices of progress. The natural character is strong, and for its development no attention is necessary: its complement, the acquired character, is weak, 
and must be kept active. In order that the strong may thrive, these weak acquired characters must be transmitted by conscious effort through imitation and by education. The conscious process acting upon the acquired character builds up what the natural process tends to dwarf. It thus preserves social equality and makes new progress in differentiation possible.

Through elimination the really strong is cut off at the point where it becomes weak, and the survivor is the undifferentiated - the mediocre - who is strong in struggle because he has that unspecialized unity upon which independent action depends. Genius, however, is a well-supported differentiation, not a net addition to the powers of men. To be mediocre is to be, not organically weak, but organically undifferentiated. Elimination does not act against the mediocre, but is in their favor. ${ }^{1}$

1 The selfish, like the mediocre, represent the undifferentiated neutral state in which life took its start. In the delicate and numerous equilibriums of an organism its activities and consumption must also be varied and harmonious. It cannot move far in any one way without setting devolution at work. While egoism represents a neutral state, altruism represents an elaborate balancing. of physical forces and grows in force as organisms rise in the scale of being. Its basis is physical, not psychic. 
Mediocre men must be elevated by the awakening of their natural powers and by an acquired ability to offset their natural weaknesses. The transformation of the mediocre is through the emotions, which cut away and regenerate without the destruction of death. Each retreat and advance differentiates and evokes new natural powers: the whole race is elevated and stupidity disappears, not by elimination, but by regeneration, which is the power to reform. Every being may be acted on by the emotional forces which mould character. It is the true aim of reform to free these forces in action and to let the natural characters evoked by them work out the salvation of the race. They can be trusted to do their work after conscious effort has surmounted the initial difficulties.

\section{SUMMARY}

I. The characters of men improve, not by addition, but by differentiation. To be strong in one direction is to be weak in another, and the deficiency must be made up by conscious education.

2. The strong can care for itself, as it has a natural background and each new differentiation adds to its natural 
strength. The opposite differentiation by becoming dwarfed loses its natural support. It is kept active only by conscious attention.

3. Reform should therefore be directed toward helping the weak. The blocks to progress lie in the aggressions of the strong which prevent the weak from getting in the current of differentiation which evokes natural characters. A backward race does not have to be made over to fit it for civilization. Most of the desired changes will come spontaneously if the initial evils are removed.

4. The strong inherit the natural changes of advantage to men, but the weak grow weaker through these changes and must receive more aid from the strong in order to restore the equality. In this equality common emotions and a social surplus in which all participate are necessary. The emotions cut all down to a common starting-point, and the surplus creates similar growth in all. Emotional changes will act on any class which has the surplus upon which growth and regeneration depend.

5. There can be no progress without an acquired equality. Each race and class should in turn impress its natural characters on those who lack them. When this is done, new differentiations bring new natural characters, and in the adjustment which follows a surplus arises that may be used to find a new equality by means of developing acquired characters in the weak.

6. Genius is a differentiation, not an addition to the powers of men. The mediocre are the undifferentiated. They must be transformed by emotions that cut back and regenerate, but do not destroy. Every person can be acted upon by the emotional forces which mould character. Reform merely sets these forces in action and lets the development 
of natural characters do the rest. They need no help when once aroused.

7. It is the democratic bringing of all up to the level of the best and not the formation of new characters that should be the conscious aim of man. Nature will care for progress if men will care for reform. 


\section{CHAPTER XVI}

The Result

Our leading question has been: How is the social surplus of an epoch transformed into permanent conditions and mental traits? This, as we now see it, divides into several questions, the answers to which must conform. Does progress start from a deficit or from a surplus? Does genius come by additions or differentiation? Does education improve natural or acquired characters? Does reform come through strengthening the strong or by helping the weak?

In all this the concrete problem really is: Does progress start from a deficit or from a surplus? Current biology and classical economics unite in making a deficit the initial force in progress. It is well known that Darwin took his clew from Malthus, but it is not often perceived how intimately the pessimism 
of the classical economists is related to the process of elimination as presented in biology. And in support of these doctrines is also much of current morality and religion. That morality begins in poverty and disappears in prosperity, and that salvation is for the poor alone, are preached with vigor in many ways. If the premise on which all this rests is faulty, many conclusions must be summarily rejected that viewed empirically seem to have a sound basis. The field is then cleared in a way that makes new evidence attainable, and this evidence will have a far higher value than any mere discussion of particular points could have. The reader should come back to this preliminary question at every point, and must reject this or that mass of evidence as he decides this question in the one way or the other. If he decides with me that progress starts with a surplus, his decision on the other debatable points will also be with me.

The economic process begins with a surplus and ends in a return flow of goods from the strong to the weak. The biologic process begins also with a surplus but ends in a com- 
plementary differentiation. By this process genius, greatness, and other sought qualities are made. Equality is a conscious tendency with no natural background. The unconscious tendency is toward differentiation and the inequality of strong, natural characters. The two processes are thus supplementary. If the economic process furnishes the material in the shape of a widely diffused surplus, the biologic process, when once started, will work itself out unconsciously. Men need not think of it, but they must think and plan for equality. It depends on the reversal of the natural process by which the strong in men becomes stronger. If, then, men work for genius and neglect equality, they get neither; but if they work for equality, they gain both genius and equality. The one is the natural and the other the acquired result of a surplus. Each deficit leads to some elimination and each surplus to some differentiation. Deficits, therefore, eliminate the weak, while differentiations create genius and the natural characters through which it expresses itself. But we should not forget that with every strong 
natural character is a weak acquired one which needs aid in its development; and for every person and class strong in some particular, there are others increasingly weak and more dependent upon the strong for their complementary relations. Men are all strong and they are all weak. The development of the strong should be, not where they are strong, but where they are weak. Only when this is clearly seen does the theory of progress become a working hypothesis in conformity with practice.

The vital point in all progress, then, is the creation of a social surplus. It will make both a biologic and an economic circuit; and each circuit will end in stronger characters and more equality. A social surplus should, therefore, be a perpetual fund always disappearing but ever reappearing in some new form. The parallel changes in economic and biologic life will thus run into each other and be expressions of the same ultimate forces. The facts in one field must correspond to those in the other and be illustrations of the adjustment to nature that man is seeking. 
The primary avenue of the exit for surplus energy is reproduction. The simplest organisms have no other means of utilizing it. The secondary avenue for the exit of a surplus is growth - the duplication of parts which remain united in a whole. But the end is not here, for when energy goes out in growth, it must finally come back to reproduction. All vital series, no matter how long, must culminate in reproduction.

Of these indirect series there are two kinds, - simple and complex. In a simple multicellular organism the series is growth, folds, ovaries, and sex products. Growth if rapid is unequal and its inequalities are the cause of folds, which become ovaries from which sex products are emitted. Complex organisms have no more elements than these, but they are united in more striking combinations. The series now becomes growth, folds, ovaries, renewed growth, enclosed sex products, nerves, emotions, reductions, regenerations, renewed growth, ovaries, exposed sex products, and then reproduction. These complex multicellular organisms differ from simple organisms in that they are double. 
Growth through an internal series of changes fails of its ultimate goal; but external growth, duplicating the internal series, is enabled, by its position, to complete the series and to end in reproduction. Complex organisms, have an equilibrium to maintain between internal and external growth - a fact which explains why they are not merely simple organisms on a larger scale and with more surplus. The maintenance of equilibrium gives rise to the peculiar problems of complex organisms.

The first of these is the problem of life, as seen in the simplest unicellular organisms; it is probable that this life depends upon certain chemical and physical principles, many of which are now well known. But we need not wait for a complete solution of difficulties in our way here before answering our central question, because the particular facts on which we depend are so well established. When additional primary laws are discovered dealing with life, they must incorporate the secondary laws with which we are familiar. It is safe, therefore, to accept the prevailing biologic 
doctrine of cell life and to use its conclusions as premises in further discussion.

It does not, however, seem to me that biologists are equally clear about the second problem, that of growth as separate from that of life. I have tried to state it in a simple and distinct form. The duplication of parts has its own laws independent of those of life, and when they are dominant, simple multicellular organisms result with the same vital principles that unicellular organisms have, but with a complexity that arises from the differentiation of parts.

The third problem has to do with the equilibrium found between organisms with a double growth and its effects in nerves and consciousness. Emotions are the great factor in the equilibrium and they act through reductions and regeneration, which gives a harmony to parts that would otherwise be divergent in their tendencies. Organs are, in fact, organisms reduced to harmony after many regenerations, but at the same time so differentiated that the action of each supplements that of the others. 
The fourth problem is that of survival, and here perhaps the widest departure from current views appears. Survival has been made primary in the doctrines of Darwin; but may not survival be but an accident and not the cause of the essential features on which life and growth depend? Let life and growth become complex, and survival acts effectively; but it is not the cause of the forces that produce complexity and differentiation. They exist in their own right and work out their ends regardless of survival. By survival the laws of life and growth have neither been made nor influenced. The simplest life has all the principles of the fittest life, but these elements are not so often repeated and moulded into new combinations.

Man is the highest form of multicellular organisms, and his evolution has all the complexity that the preceding stages permit. In unicellular organisms, or even in simple multicellular organisms, progress is through elimination, but when differentiations appear in men, both of them persist and are brought into harmony by some division of labor or of function. 
The first of these differentiations is that of mind and body. Between the two there is no sharp demarcation. The one is merely more mind than body, and the other is more body than mind. A second differentiation is between the sensory and motor organs. Here again we find highly differentiated functions but no sharp limits; the sensory organs have some motor functions and the motor organs contain elements that would, under favorable conditions, transmit afferent impulses. A third differentiation results in acquired and natural characters. Natural characters have inherited organic connections by which each action or function follows directly after its organic antecedent. Acquired characters are linked in consciousness. The two elements thus united had their organic beginnings at different stages of evolution, and thus are in their evolution independent. The conscious element needed to unite them is a mental association.

Another differentiation is between organs of action and organs of control. The conscious, the sensory, the acquired, dominate the organs of 
movement and create for them their environment. This makes a marked difference between the adjustment of an animal and man. The motor organs of simple organisms come in contact with the physical environment, and react directly against it. The motor organs of men are sheltered. The foot or hand does not touch the real environment on which survival depends, but reacts against an environment created for it by the organs of control. The real object that determines why a man in New York survives may be a thousand miles away. There is thus for man environment within environment, each depending on an exterior one against which it reacts.

Distinction must also be drawn between natural and acquired organs of expression, - the hand and foot being in the first class, the tool or machine belonging to the second. So too there are natural and acquired organs of impression. The eye and ear are natural, while the telephone, the newspaper, and art products are acquired organs of impression. These acquired organs make up the capital of a nation, and to the concrete goods com- 
posing it are the natural organs of men adjusted. Capital is thus an environment between men and nature, and through it go the currents of expression or of impression that fix men's relations to the physical world.

When a man is compared with a simple organism, all these acquired organs must be thought of as parts of the man, if his relations to nature are to be pictured as simply as are the relations between a simple organism and its environment. To apply to man the theory of survival we must use a concept of man that makes these acquired organs a part of him. Elimination for the simple organism means the cutting off or the crippling of some natural organ, and thus the destruction of life. With men it may mean merely the breaking down of an acquired organ not affecting life. A contest between men is decided when some mechanism used by one party breaks down; it is not carried to a life and death struggle. One party yields when its property is destroyed or so put in danger that further contest is useless. In a war, for example, the real contest now lies in the destruction of property. Mech- 
anisms in the form of arms, cannon, food, means of transportation, and other supplies used by one side are matched against similar agents used by their opponents, and the relative excellence of their instruments as destructive agents is thus determined.

There is, it is true, a destruction of life, but it is only an incident to the destruction of property, through which the real contest is decided. The poorer instruments are eliminated by the contest, but not the poorer men. So far as men are killed off, it is probably the best men on each side that die. It is not this loss of men that modifies society, but the emotions of those who see or hear of the destruction of life and property. So too, when two nations or classes contest in the industrial field, the struggle ends when the material equipment of the one is shown to be inferior. Selection and elimination act on these tools, but not on the men. The emotional effect of this destruction is an industrial depression which alone produces an abiding effect on men. Contests between men are thus usually decided within the realm of wealth; if they go farther, they 
destroy the mental associations by which the acquired characters are linked. I doubt if contests now go far enough to eliminate natural characters. These are brought into accord with their environment of acquired characters and of acquired organs by emotional changes that cut back and then permit regeneration to develop a form harmonizing with the new conditions. Emotion is thus the agent of harmony between the various natural and acquired organs. It modifies but does not destroy. Selection results from destruction, but in the case of man it is the destruction of mechanisms and not life. Human progress is not therefore due solely to the action of selection. The play of emotion is equally effective, and in the case of natural characters it is perhaps the sole agent of progress.

Progress in man is by differentiation and is a problem of equilibrium. There are no additions to the elements of cell life. When they change it is by a differentiation from a neutral centre, which creates an equilibrium by means of the utilization of both differentiated parts. Modifications of structure in one 


\section{The Result}

direction are matched by those in the other. Both parts are retained and none is eliminated. Every complex organism has the same equilibrium that is maintained in the undifferentiated unicellular organism, but to gain its complexity it moves out in both directions and utilizes here what is a waste product there. These are the complementary differentiations which add to the natural characters. The elimination of differentiations, that is, of those which end in the rejection of one part, is a backward step tending to restore the original neutrality. Such an elimination fails to fulfil the conditions of growth and throws organisms back to their neutral beginnings. Struggling organisms acquire an independence which aids in survival, but it is at the expense of the differentiations that make for progress. The cause of progress lies in the increase of energy which prosperity creates, and not in the eliminations due to adverse conditions. Remove the surplus and there is no progress; restore it and there is no elimination. The changes that make for progress are emotional and do not destroy, but reduce and allow 
regeneration to restore harmony and simplicity. There is an ever onward movement so long as favorable conditions create growth which ends in additions, and unfavorable conditions arouse emotions which end in regeneration and harmony.

Character building is not an elimination but a complementary differentiation. Its processes carry farther the same changes which transform the embryo. It is surplus energy creating new antagonisms which end only in the destruction and regeneration of some organ along new lines. We are not born with characters; they are made by regeneration. The internal body grows and changes through life, as the external body does in the embryo and in youth. Character is the internal body articulated as the external body is articulated, by its early contact with the environment. It is an expression not of will, but of surplus energy. We get character by doing, not by willing. It results from the transforming of thoughts into activity.

In closing, a word of personal history may not be out of place. The principles here enun- 
ciated have not always been clearly seen by me. I began with a much simpler programme and strove to put progress into fewer categories by measuring it through the initial stages of the dynamic movements with which young nations start. Here, I thought, is the normal phenomena, and all else represents some past influence no longer active. Free life from its restrictions, and we have a pleasure economy and a normal order of progress. The natural curve of thought would move from concrete economic events upward to its highest forms. Nothing is real progress which does not form a part of this curve.

But this rigid concept to which I so persistently held overlooks the influence of heredity. At length I saw that after economic epochs cease to exist, they live in the mental life they have created. Character, in the sense of inherited traits, has its curve of thought with as strong and clear an outline as that which marks the stress of economic conditions. Thought, I then said, has two curves, and nothing is normal until it reveals the movements of both. A picture of English civilization I assumed to be 
more typical than one of American progress, in which the economic motives are so distinctly uppermost.

I am now compelled to make another change and to seek the normal in a new direction. It was my belief, as I think it is the common belief as well, that the upbuilding forces in national life are effective early in its development, and that the destructive forces, coming later in a body, made a period of decay; we say, for instance, that nations have a period of youth, maturity, and old age. But this analogy now seems fallacious. Life is not a simple upbuilding process followed by decay. Death is an accident to life, not a necessity. The destructive or devolutional forces are always at work, even at the beginning; but in their normal function they create change, not death. Devolution is an essential part to progress. The upbuilding process continues only as life is cut back to create more vigorous growth. The normal, therefore, lies still farther away than I had supposed from those youthful periods when there are many additions but no change. There is nothing normal on which emotion 
does not act and in which emotional changes are not visible. They give a simplicity to life which growth through economic changes cannot parallel. Thought must therefore have an emotional as well as an economic curve, and this in its broader aspects may prove to be social as contrasted with economic progress. At least the two fields appear more clearly distinct than ever before, and I have greater hope that a definite line of demarcation may be drawn between them. 



\section{GENERAL SUMMARY}

IT may not be out of place to state the general principles of which use has been made apart from the concrete problems in which they appear.

I. Growth and cell division. Organisms under favorable conditions accumulate energy which results in growth. This increase of mass is counteracted by cell division, which tends to reduce the size of individual organisms and to increase their number.

2. Surface unity and internal differentiation. The disruptive forces act more powerfully at the centres of organisms than at the surface. The tendency to divide appears first at two internal centrosomes and gradually extends outward. This may be due to inadequate exits for waste products. The surface or envelope thus becomes stronger and grows more rapidly than the interior. Folds result and cause many subsequent complexities. The disruptive tendencies in the interior are reduced by differentiations which so complement each part that what is not utilized by the one is food for the other. The amount of waste material is thus reduced and the organism correspondingly strengthened.

3. Double organisms. This internal tendency to divide and to differentiate causes the higher organisms to become practically if not in reality double. The differentiation of mind from body and the bilateral divisions of the body are instances of this tendency. 
4. Growth and reproduction. Growth is more simple and dominant at the surface than in the interior, and as a result reproduction dominates first in the interior. Confined sex products result, which must break through the envelope to obtain an independent existence. When they fail they are transformed into nerve tissue, useful in preserving the unity of the organism.

5. Emotional harmony. The internal differentiations and the confinement of sex products destroy the internal unity of the organism. Each part tends to become independent. The unity of the organism is not mechanical but emotional. Each part devolves until the growth forces in it become dominant and then it evolves along new lines. This happens again and again until the emotional shocks act on each part alike. Then an emotional harmony arises that preserves the organism and increases effectiveness.

6. Natural vs. acquired characters. The great mass of social customs, habits, and traditions are acquired characters and are not inherited. They are due to the direct action of the present environment. Acquired qualities increase energy, which impels the possessor into new environments. Each new environment tends to develop acquired characters, through which the environment is better utilized, and these characters become primary by a movement into a new environment. Whatever natural character men have, the race acquired in some previous environment.

7. Use is not the cause of characters, but the result of their appearance. Animals do not develop teeth because they eat hard food; they eat hard food because they have teeth. Use creates surplus energy, which acts in a way to develop undifferentiated parts. Secondary characters thus 
arise, and the species moves into an environment where these characters are necessary, hence primary.

8. Natural selection and emotion. Natural selection assumes that improvement is wrought out by the elimination of the weak. But emotion, like a far-reaching nervous system, extends out widely into the environment, and beings are strongly affected by it who are not directly involved in a given event, as when a man sees or hears of an accident. Emotion, then, in arresting development or in cutting back to a simpler state adjusts the organism more quickly to its changed environment than is done by natural selection.

9. Consciousness, will, and memory are, physiologically, properties of the ultimate germ cell. Consciousness is confined to katabolic epochs. Memory is a phenomenon of related parts, a record of some growth or change in the tissues, accompanying a change of direction of nerve currents and of activity. Will is the psychic expression of a reaction after an emotional devolution. A strong will is indicative of dominant katabolism.

Io. Surplus and deficit vs. character and tradition. An economic surplus furnishes energy resulting in growth, which induces emotional changes, so disturbing present adjustment of organism to environment. This impels contention with the environment, or a migration to a new environment, so giving rise to a change in character. An economic deficit blocks the first step in the series of changes. It prevents the formation of new tissues, organs, or customs, and hardens or fixes those already in use. Deficits build tradition, morality, imitation, and force upon each age the acquired characters of past ages. Selfishness is a consciously acquired aptitude due to existence under 
conditions which have created a deficit. Deficits end in a moral code, impressing motives of economy and self-assertion.

II. The agents of acquired characters. Imitation is a primitive means of adjustment; the mechanism of it is inherited by the inner neural body, and affords acquired characters a method of propagation. Fear in weak organisms is the very best protection against extinction. It is a natural character, but still very effective in establishment of acquired characters. Reason is a property of the lowliest organisms; it is in essence a recoil from the dissimilar and an acceptance of the similar. Discipline acts on outer organs of expression, making them so rigid that impulses pass inward or regenerate the primitive organs utilized by acquired characters.

I2. The problem of education is not one of addition. It is wholly a matter of acquiring character. It is a strengthening of the strong where they are weak, - a creation of equality which the process of natural differentiation tends to prevent.

13. Progress is not the making of the strong, but that protection of the weak in men by which differentiation becomes possible. This strengthening of the weak is not final, but must be repeated in each generation with increasing care. Give the dwarfed character a surplus, and spontaneous changes will reorganize society. The cause of progress lies in the increase of energy which prosperity creates and not in the elimination due to adverse conditions. Remove the surplus and there is no progress; restore it and there is no elimination. The vital point in all progress is the creation of a social surplus. 


\title{
THE DEVELOPMENT OF ENGLISH THOUGHT
}

\author{
A Study in the Economic Interpretation of History \\ By SIMON N. PATTEN, Ph.D. \\ Professor of Political Economy, University of Pennsyluania \\ Cloth Crown 8vo \$3.00, net
}

\section{COMMENTS}

"What is perhaps most remarkable about the general treatment of the subject is the breadth of view kept in mind - having constant regard to the higher moral, religious, and intellectual aspects of English life quite as much as its more material characteristics. . . . It is decidedly one of the best written and most thoughtful of recent books." - Tribune, Chicago.

"Keen in its analysis, novel in its positions, and striking in its relationships of fact and principle is the author's discussion. . . . To a subject full of interest in these days the author has brought a novel point of view, which finds expression in seeming paradoxes and an abundance of pithy aphoristic propositions which surprise and delight the reader." - The Philadelphia Times.

"The economic interpretation of history is a distinctly modern idea. It has had a place in numerous recent books, but we do not recall any volume of importance where it is applied with the searching philosophical thoroughness of the present work. The author's logic and his observation are alike sound, and his grasp of the broad aspect of English development appears in every chapter. The presentation of the subject is scholarly, the terminology is accurate, the definitions are clear and almost always satisfactory, and the impression left on a thoughtful reader's mind is that of admiration at the scope and method of the work and interest in its intellectual offering." - The Transcript, Portland, Me.

\section{THE MACMILLAN COMPANY}

66 FIFTH AVENUE, NEW YORK 


\section{THE THEORY OF PROSPERITY}

BY

SIMON N. PATTEN, Ph.D.

Author of "The Development of English Thought," etc.

\section{Cloth $12 \mathrm{mo} \$ 1.25$, net}

\section{COMMENTS}

"The whole discussion is most sane and clear, and deserves the attention of every thinker on social subjects."

- The American Journal of Sociology.

"A thorough and logical discussion . . . well worth consideration, study, and possession as a book of reference."

- Courier Journal.

"Well worth the careful consideration of every person interested in the social and economic well-being of the people."

- Baltimore Sun.

"It is a work which calls for a careful reading . . . one of those books that make a strong appeal to the student interested in economic problems." - Brooklyn Daily Eagle.

\section{THE MACMILLAN COMPANY}

heredity

66 FIFTH AVENUE, NEW YORK 



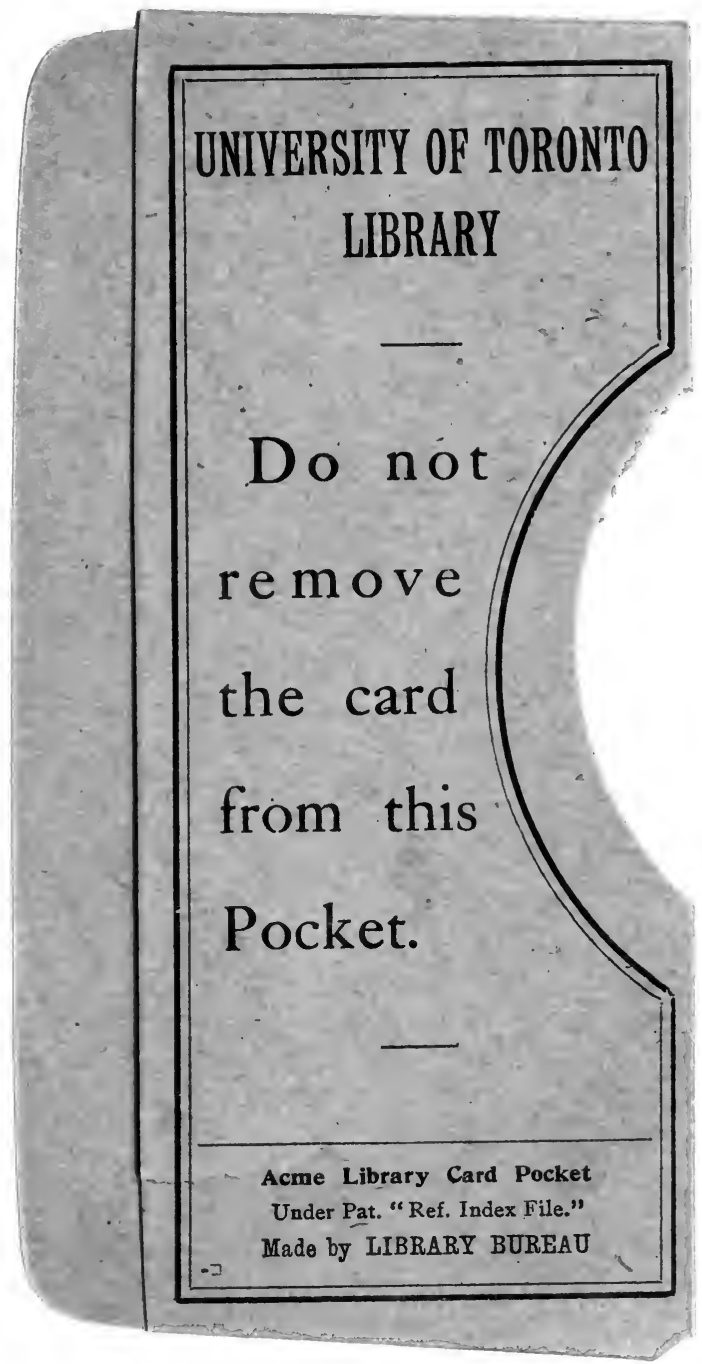


